
\title{
$\begin{array}{ll}\text { Research Square } & \begin{array}{l}\text { Preprints are preliminary reports that have not undergone peer review. } \\ \text { They should not be considered conclusive, used to inform clinical practice, } \\ \text { or referenced by the media as validated information. }\end{array}\end{array}$
}

\section{Transcriptome Analysis of Aconitum carmichaelii and Exploration of the Salsolinol Biosynthetic Pathway}

Yuxia Yang

Sichuan Academy of traditional Chinese Medical Sciences

Ping Hu

Sichuan Academy of Medical Sciences and Sichuan People's Hospital

Xianjian Zhou

Sichuan Academy of traditonal Chinese Medical Sciences

Ping Wu

Sichuan Academy of trditional Chinese Medical Sciences

Xinxin Si

Sichuan Academy of traditional Chinese Medicine Science

Bo Lu

Sichuan Academy of traditional Chinese Medical Sciences

Yanxi Zhu

Chengdu University of pharmacy and biological engineering

Yanli Xia ( 550522386@qq.com)

chengdu university of pharmacy and biological engineering https://orcid.org/0000-0003-1542-3084

\section{Research article}

Keywords: Aconitum carmichaelii, alkaloid, C19-diterpenoid alkaloids, Salsolinol, Biosynthetic pathways, Varieties

Posted Date: June 10th, 2019

DOI: https://doi.org/10.21203/rs.2.10189/v1

License: (c) (i) This work is licensed under a Creative Commons Attribution 4.0 International License. Read Full License

Version of Record: A version of this preprint was published at Fitoterapia on January 1st, 2020. See the published version at https://doi.org/10.1016/j.fitote.2019.104412. 


\section{Abstract}

Background Aconitum carmichaelii has been used in traditional Chinese medicine for treating various diseases for several thousand years. The biosynthetic pathway of some alkaloids such as C19-diterpenoid alkaloids has been reported, but pathways in different varieties of A. carmichaelii remain unknown. Herein, we performed transcriptome analysis of varieties A. carmichaelii and characterized the biosynthetic pathway of salsolinol. The results expand our knowledge of alkaloids biosynthesis, and provide a theoretical basis for analysing differences in alkaloids biosynthesis patterns in different varieties. Results A total of 56 million raw reads $(8.28 \mathrm{G})$ and 55 million clean reads $(8.24 \mathrm{G})$ were obtained from two varieties (Z175 and R184) leaf transcriptomes, respectively, and 176,793 unigenes were annotated using six protein databases. This yielded 6,873 differentially expressed genes (DEGs) in the two varieties, of which 281 are involved in the salsolinol biosynthetic pathway, including 158 and 75 related to glycolysis and the shikimate pathway, respectively. Furthermore, $843 \mathrm{DEGs}$ were found to be involved in the formation of C19-diterpenoid alkaloids, with 34 differed between the two varieties. These target genes were analysed to explore differences in C19-diterpenoid alkaloid biosynthesis in Z175 and R184. In addition, 322 DEGs encoding transcription factors potentially related to alkaloid accumulation were identified. Conclusions The biosynthesis pathway for C19-diterpenoid alkaloids and salsolinol included 34 and 24 DEGs in Z175 and R184, respectively. Thus, genes involved in alkaloid biosynthesis and accumulation differ between varieties. The mechanisms underlying the differences and their relevance require further exploration.

\section{Background}

The Aconitum genus (Ranunculaceae), currently including 211 known species, is described as one of the 'Four Pillars' of ancient herbs used in Chinese medicinal healing, of which 400 are distributed in temperate regions of the northern hemisphere [1, 2]. The lateral roots of Aconitum have been widely used in traditional Chinese medicine (TCM) to treat various diseases and ailments for several thousand years, including fainting, rheumatic fever, painful joints, gastroenteritis, diarrhea, edema, bronchial asthma, and some endocrinal disorders such as irregular menstruation [3]. Approximately 76 species in the Aconitum genus are used for medicines in China. A. carmichaelii is one of two species officially recorded as an aconite in the Chinese Pharmacopoeia [4]. This perennial plant grows to a height of $60-150 \mathrm{~cm}$, has dark brown roots, palmately divided dark green glossy leaves and violet flowers with helmet-shaped petals [3]. The primary root of $A$. carmichaelii is known as chuanwu (ㅁ) in TCM, and the lateral root is called fuzi (ㅁ) [ 5]. A. carmichaelii is mainly grown in Sichuan, Yunnan and Shanxi provinces in China [6]. However, the high toxicity risk and narrow therapeutic range limit large-scale medicinal applications [7].

The pharmacological properties of $A$. carmichaelii are attributed to the accumulation of a diverse range of bioactive C20-, C19- and C18-type diterpene alkaloids (DAs). To date, 75 C19-DAs, 18 C20-DAs and 11 other alkaloids have been identified from the root of $A$. carmichaelii [8, 9], but the content of toxic DAs in tubers makes this herb particularly dangerous. More than 1500 DAs have been isolated from Aconitum, but only lappaconitine, 3-acetylaconitine and bulleyaconitine have been clinically used as analgesics in China [10]. Furthermore, the cardio- and neurotoxicity of these DAs makes them potentially lethal, and the improper use of Aconitum in China, India, Japan and elsewhere still results in human poisoning [4]. The toxicity of Aconitum DAs arises from their effect on voltage-gated sodium channels, the release of neurotransmitters and changes in receptors, and the promotion of lipid peroxidation and cell apoptosis in the heart, liver and other tissues [9]. The principal toxic and pharmacological ingredients of fuzi are aconitine-type C19-DAs [5, 9].

In Aconitum, DAs and their derivatives, including C18, C19 and C20 classes, are the principal constituents responsible for biological activity [11]. C19-DAs in processed roots of Aconitum following hydrolysis are possibly the most beneficial bioactive constituents of fuzi [12]. The majority of C19-type diterpene alkaloid skeletons, which account for most of the alkaloid content of $A$. carmichaelii, are derived from various substitutions on the aconitine skeleton, leading to 75 different known alkaloids [9]. Mevalonate (MVA) and methylerythritol (MEP) pathways play important roles in the biosynthesis of terpenoids [11], and biosynthesis of C19-DAs in A. carmichaelii begins with MVA and MEP biosynthetic pathways, involving geranylgeranyl pyrophosphate synthase (GGPPS) that produce the precursor of DAs [13]. Furthermore, ent-CPP synthases (CPS), ent-kaurene synthases (KS), kaurene oxidases (KOX), cyclases, aminotransferases, monooxygenases, methyltransferase and BAHD acyltransferases act together to synthesis C19-DAs in fuzi, and transcription factors (TFs) appear to regulate the accumulation of DAs.

C19-DAs and C18-DAs may be derived biogenetically from C20-DAs [14, 15] via the loss of carbon atom(s) [16]. Salsolinol, an alkaloid involved in the black appearance of overripe bananas [17], is biosynthesized by nonenzymatic Pictet-Spengler condensation, in which a phenylethylamine such as dopamine complexes with acetaldehyde to form an imine, which subsequently cyclizes to generate a tetrahydroisoquinoline [18]. In medical science, salsolinol (1methyl-6,7-dihydroxy-1,2,3,4-tetrahydroisoquinoline) is structurally similar to 1-methyl-4-phenyl-1,2,3,6-tetrahydropyridine, which is reported to play a role in the development of Parkinson-like syndrome [19]. Although barely soluble in water [20], salsolinol functions in bradycardiac arrhythmia and decreases blood pressure [11]. Current knowledge on salsolinol biosynthesis in Aconitum is minimal.

In A. carmichaelii, C19-type diterpenes are the most abundant DAs, followed by C20-type and other diterpenes [9]. High-performance liquid chromatography (HPLC) analysis with an evaporative scattering light detector (ELSD) carried out on roots from Z175 and Z184 varieties in 2016 and 2017 identified C19diterpenoid alkaloids including benzoylaconine, hypaconitine, neoline, mesaconitine, benzoylmesaconine, fuziline, aconitine, talatizamine, mesaconine, hypaconine and aconine, as well as the C20-diterpenoid alkaloid songorine, and one other alkaloid, salsolinol (unpublished data). Analysis of expression patterns of unigenes involved in C19-type diterpene biosynthesis in different tissues showed that flowers and buds are the most transcriptionally active tissues, while roots and leaves are characterized by a distinct set of transcriptionally active unigenes [13]. Herein, differences in alkaloid content in different $A$. carmichaelii varieties and expression patterns in different tissues were investigated. Transcriptome data were acquired from two varieties, and salsolinol biosynthesis pathway-related genes were identified. Finally, differences in diterpenoid alkaloid content and enzymes mediating biosynthesis of C19-DAs were compared.

\section{Results}


In total, 56 million raw reads (8.28G) and 55 million clean reads (8.24G) were obtained from six transcriptomes Z175 and R184 varieties in three biological replicates, respectively. In Z175, the percentage of reads with q20 and q30 quality scores was $97.32 \%$ and $92.61 \%$, compared with $97.61 \%$ and $93.26 \%$ for R184 (Fig.1). After trimming adapters, removing low-quality raw sequences using Trimmomatic (http://www.usadellab.org/cms/index.php?page= trimmomatic), splicing and assembly (using Trinity), we obtained 187 million transcripts from the six leaf transcriptomes of $A$. carmichaelii, with an N50 value of 1,309 bp, an average length of $853 \mathrm{bp}$, and a maximal length of 11,085 bp. The six raw read datasets have been deposited in the NCBI SRA database under GenBank accession number SUB5660984 (biosample, RAW data is submitting to NCBI SRA with some submitting problem).

\section{Homology analysis and Gene Ontology (GO) annotation}

From 108,477 unigenes (61.35\%), we obtained matches to entries in the NCBI non-redundant (nr) protein database using BLASTx with an E-value cut-off of 1 e-5 (Fig. 2a). Meanwhile, 54,936 (31.07\%) were aligned to the NCBI nucleotide sequences (Nt) database, 82,039 (46.40\%) were aligned to the Swiss-Prot database, 77,612 (43.89\%) were aligned to the protein family (Pfam) database, 78,500 (44.4\%) were aligned to the G0 database, and 27,522 (15.56\%) were aligned to the Clusters of euKaryotic Ortholog Groups (KOG) database (Fig. 2a). Interestingly, 1,837, 24,380 and 40 unigenes were uniquely annotated to Nt, nr and KOG, respectively (Fig. 2c). Furthermore, 176,793 unigenes were annotated to at least one of the searched databases, and $35.4 \%$ of unigenes were successfully aligned to Nelumbo nucifera genes using BLASTx, followed by Vitis vinifera (12.5\%), Theobroma cacao (2.9\%), Jatropha curcas (2.4\%) and Citrus sinensis (2.0\%), and $44.8 \%$ were aligned with other species (Fig. 2 b).

We used GO annotations to classify the 78,500 unigenes into functional groups using BLAST2GO where $p$-values calculated by hypergeometric distribution tests and E-values were $<1 \times 10-5$. In the A. carmichaelii transcriptome data, biological process accounted for the majority of G0 annotations ( $47.33 \%$, 179,968 genes), followed by cellular component $(28.10 \%, 106,856$ genes) and molecular functions $(24.57 \%, 93,447$ genes). In the biological process category, GO terms related to cellular process $(23.43 \%)$ and metabolic process $(22.29 \%)$ were most abundant, followed by single-organism process ( $16.62 \%)$, biological regulation (7.14\%) and regulation of biological process (6.61\%). In the cellular component category, cell (19.88\%) and cell part (19.87\%) were dominant, followed by organelle (13.39\%), macromolecular complex (12.69\%) and membrane (10.48\%). In the molecular function category, binding (48.70\%) and catalytic activity (38.03\%) were the most represented, followed by catalytic activity and transporter activity (4.67\%), structural molecule activity (2.50\%) and nucleic acid binding transcription factor activity (2.11\%; Fig. 3a).

A total of 30,657 transcripts were classified into 26 KOG categories. General function prediction (7,602 transcripts, $24.80 \%)$ was the dominant KOG category, followed by posttranslational modification, protein turnover and chaperones (4,267 transcripts, $13.91 \%)$ and general function prediction only (3,335 transcripts, 10.88\%; Fig. 3b).

To elucidate active biosynthesis pathways in A. carmichaelii, annotation of nr data using the Kyoto Encyclopedia of Genes and Genomes (KEGG) database identified 43,695 genes assigned to five main categories representing 130 biological pathways. The highest number of KO identifiers were linked to metabolism (18,951 genes) followed by genetic information processing ( 9,809 genes), cellular processes (1,813 genes), organismal systems ( 1,410 genes) and environmental information processing (1,372 genes). Pathways with the largest number of KO identifiers were: translation (4,070); carbohydrate metabolism (3,808); folding, sorting and degradation (3133); overview (2,895); amino acid metabolism $(2,210)$ and lipid metabolism (1,974; Fig. 3c).

A total of 4,866 transcripts (2.75\%) were assigned to 80 TF families. Among these, MYB (308), C3H (249), AP2-EREBP (199), NAC (195), Orphan (190) and $\mathrm{C} 2 \mathrm{H} 2$ (185) were the most abundant. Furthermore, 322 (6.62\%) differentially expressed genes (DEGs) encoding TFs potentially involved in the regulation of various physiological processes and biochemical pathways in A. carmichaelii were identified (Additional file1,table S1).

\section{Tissue-specific differential gene expression}

Expression of read-mapped genes was analysed based on the fragments per kilobase of transcript per million mapped reads (FPKM) value for each clean read. Transcripts with |log2FoldChange| $>1$ and padj $<0.05$ were considered DEGs. Among the 176,793 identified unigenes, 6,873 DEGs were detected, of which 3,470 were down-regulated and 3,403 were upregulated in the two $A$. carmichaelii varieties. A total of 4,175 DEGs were linked to 356 metabolic pathways ( $p$-value <0.05). Based on DEGs between Z175 and R184 varieties, GO analysis showed that 2,076 GO accessions matched biological process, 454 matched cellular component, and 993 matched molecular function categories (Fig. 4). KEGG analysis identified 320 pathways related to 4,175 annotated DEGs ( $p$-value $<0.05$; Additional file1, t able S2).

\section{Characterization and expression analysis of unigenes involved in C19-type diterpene biosynthesis in Z175 and R184.}

Based on the results of previous studies $[13,21]$, putative unigenes involved in the aconitine biosynthesis pathway were identified, including 49 unigenes encoding 1-deoxy-D-xylulose-5-phosphatesynthase (DXS), two of which were more highly expressed in Z175 than R184, 1 1-deoxy-D-xylulose-5-phosphate reductoisomerase (DXR), 10 2-C-methyl-D-erythritol 4-phosphate cytidylyltransferase (ISPD), five 4-(cytidine-50-diphospho)-2-C-methyl-D-erythritol kinase (ISPE), two 2-C-methyl-D -erythritol2,4-cyclodiphosphate synthase (ISPF), 1I (E)-4-hydroxy-3-methylbut- 2-enyldiphosphate synthase (ISPG), two (E)-4-hydroxy3-methylbut-2- enyldiphosphate reductase (ISPH), and four isopentenyl diphosphate isomerase (IPPI) in the MEP pathway (Additional file 1,table S3). Furthermore, 14 acetoacetyl-CoA thiolase (AACT) and seven 3-hydroxy-3-methylglutaryl-CoA reductase (HMGR) involved in the MVA pathway were identified, including two more highly expressed in Z175, along with two 3-hydroxy-3-methylglutaryl-CoA synthase, (HMGS), three mevalonate kinase (MVK), six phosphomevalonate kinase (PMK), and two mevalonate diphosphate decarboxylase (MVDD; Additional file 1,table S4). Five geranylgeranyl pyrophosphate synthase (GGPPS), seven CPS, 24 KS (Cluster-219.18055 more highly expressed in Z175), 21 KOX, of which four are more highly expressed in Z175, 84 cyclases, of which Cluster-219.66822 and Cluster-219.62280 were higher expressed than Z175, and Cluster-219.80709 and Cluster-219.73820 higher than R184, 131 aminotransferases, of which Cluster-219.46073 was higher expressed than R184, and Cluster-219.51635 higher than Z175, 190 monooxygenases, 
of which Cluster-219.114355, Cluster-219.51666, Cluster-219.28553 were higher expressed in Z175 than R184, and Cluster-219.140395, Cluster-219.35262 , Cluster-219.119209, Cluster-219.2681, Cluster-26892.0, Cluster-219.131122 higher than Z175, 73 BAHD acyltransferases of which Cluster-219.50148, Cluster-219.20417, Cluster-219.64576, Cluster-219.19319, Cluster-219.90737, Cluster-20871.1, Cluster-219.44720, Cluster-219.48909, Cluster-219.4883 were higher expressed in Z175 than R184, and Cluster-219.10123, Cluster-219.138567, Cluster-219.32670, Cluster-219.138566, Cluster-219.99337 higher than Z175, and 200 methyltransferases, of which Cluster-219.14882, Cluster-219.17602 were higher expressed in R184 than Z175, and Cluster-22914.0 higher than R184, were also identified (Additional file 1,table S5). Expression of all the above higher or lower unigenes was statistically significant (log2 fold-change $>1.0$ and pdaj $<0.05$ ), and the sequence of them was in Additional file 2. Expression levels of unigenes involved in the aconitine biosynthesis pathway in the two varieties are shown in Additional file 1, table S3S5. Expression levels of unigenes in the isopentenyl diphosphate pathway were highest, followed by MEP and MVA pathways (Additional file 1, table S3S5).

\section{Candidate genes encoding enzymes involved in the salsolinol biosynthesis pathway}

Salsolinol is another important aconitine in A. carmichaelii. A schematic diagram of the proposed pathway for the biosynthesis of salsolinol is shown in Fig. 5. Precursors for the biosynthesis of salsolinol are derived from D-glucose through glycolysis that generates phosphoenolpyruvate, then through the shikimate pathway that synthesizes chorismate, then through dopamine, finally yielding salsolinol. In more detail, the glycolysis pathway includes 19 hexokinase (HK) with Cluster-219.117566 higher expressed in Z175, 13 glucose-6-phosphate isomerase (GPI) with Cluster-219.75274 higher expression in Z175 than R184, 30 6-phosphofructokinase (PFK) 31 fructose-bisphosphate aldolase (ALDO), of which Cluster-219.73817, and Cluster-28961.0 were higher expression in Z175 than R184, and Cluster-219.98335, Cluster-219.14890, Cluster-219.9488 and Cluster-219.71706 higher expressed in R184, nine glyceraldehyde-3-phosphate dehydrogenase (GAPHD), 32 phosphoglycerate kinase (PGK) with Cluster-219.80323 and Cluster-219.80326 higher expression in Z175, one 2,3-bisphosphoglycerate-dependent phosphoglycerate mutase (PGAM) and 23 enolase (ENO) enzymes (Additional file 1,table S6). In the shikimate pathway, there are 22 phospho-2-dehydro-3-deoxyheptonate aldolase (AROF) enzymes, four of which, Cluster-219.50402, Cluster-219.4979, Cluster-219.95746, Cluster-219.78492 and Cluster-219.78493, were more highly expressed in Z175, two 3-dehydroquinate synthase (AROB), nine 3-dehydroquinate/shikimate dehydratase (AROD/AROE), 13 shikimate kinase (AROK), of which Cluster-219.54689 and Cluster-219.77462 were more highly expressed in R184 and Z175, two 3-phosphoshikimate 1-carboxyvinyltransferase (AROA), and 27 chorismate synthase (AROC; Table 1). The chorismate pathway includes seven chorismate mutase (CHMU), five bifunctional aspartate/glutamate aminotransferase (PAT), seven prephenate dehydrogenase (TYRC), 23 polyphenol oxidase (POX), including seven unigenes, Cluster-22607.0, Cluster-219.82880, Cluster-219.54918, Cluster-219.54917, Cluster-219.50283, Cluster-17242.0 and Cluster219.92608 more highly expression in Z175 than Z184, and six tyrosine decarboxylase (TYDC) enzymes (Table 2). All sequences of expressed statistically significant unigenes between Z175 and R184 were in Additional file 3. Comparison of unigene expression levels in glycolysis, shikimate and chorismate pathways revealed highest expression levels in glycolysis, followed by shikimate and chorismate pathways.

\section{Discussion}

Advantages such as high-throughput, accuracy and reproducibility have resulted in transcriptome sequencing becoming established as a powerful technology [22], now widely employed for deep sequencing and exploring the molecular mechanisms of various biological phenomena. Two key studies involving $A$. carmichaelii transcriptome analysis have been reported, one exploring expression in flower, bud, leaf and root tissues [13], and the other analysing rootstock and leaf tissues [21]. Both studies investigated C19- and C20-diterpenoid alkaloid biosynthetic pathways. In the study, we obtained leaf transcriptome data from two varieties of $A$. carmichaelii (Z175 and R184) to investigate potential differences in alkaloid biosynthesis and probe the physiological significance. Leaf transcriptome data showed that the average length of unigenes was $923 \mathrm{bp}$, considerably longer than $595 \mathrm{bp}$ [21] and $642 \mathrm{bp}$ [13] reported previously. From the six leaf transcriptome datasets collected in triplicate in the present work, 108,477 transcripts were annotated, compared with 128,183 transcripts from transcriptome data from four tissues [13] and 95,812 transcripts from two tissues [21]. The comparative results show that our present transcriptome sequencing and annotation analysis is significantly deeper than these previous studies. According to the latest plant TF categories [23], 4,866 transcripts were assigned to $80 \mathrm{TF}$ families, compared with only 644 transcripts assigned to 39 branches in previous work [21], but IF, MYB and C3H TFs were essentially the same. In medicinal plants, MYB and C3H TFs regulate specialized metabolic pathways, as do WRKY, ERF and bHLH TFs [11].

A. carmichaelii is a medicinal plant of high therapeutic value due to the presence of alkaloids, among which C19- and C20-diterpenoid alkaloids are the predominant groups. The active compounds in A. carmichaelii endow broad biological activities, including effects on the cardiovascular system, antiinflammation and analgesic action, anti-tumor activity, immune system effects, hypoglycemic and hypolipidemic effects, anti-aging, kidney protection and energy metabolism [9]. In the biosynthesis of aconitine, both MVA and MEP biosynthetic pathways contribute to the biosynthesis of DAs in plants [24]. A total of 843 unigenes are involved in the biosynthesis of C19-diterpenoid alkaloids, including 22 unigenes associated with the MEP pathway and 34 unigenes related to the MVA pathway, considerably more than the number identified in a previous four-tissue study [13].

In the aconitine biosynthesis pathway, unigenes related to the isopentenyl diphosphate pathway were the most highly expressed in $A$. carmichaelii leaves, followed by those in the MEP and MVA pathways, similar to previous results [13]. Several studies have reported the tissue compartmentalization of precursors, intermediates and final products in highly specialized cells, as well as in different plant tissues [25, 26], and A. carmichaelii may adopt a similar strategy for synthesizing aconitine-type DAs, which may explain the observed differences in the expression patterns of unigenes involved in different pathways. In the MEP pathway, DXS is believed to act as a bottleneck enzyme [27] and 12 unigenes representing 60 DXS enzymes were among the top 20 most highly expressed according to our current results, which indicates the importance of MEP pathways in A. carmichaelii leaves. The MVA pathway contributes metabolic intermediates for the biosynthesis of sesquiterpenoids including aromatic compounds, and plays an important role in attracting pollinators and seed disseminators [28, 29]. HMGR is believed to be a bottleneck enzyme in MVA pathways [27], and four unigenes representing eight HMGR enzymes were among the top 20 most highly expressed in our current results, which indicates the importance of MVA pathways. 
In the isopentenyl diphosphate pathway, seven aminotransferases, seven cyclases, two methyltransferase, two BAHD acyltransferases, one kaurene synthase and one ent-kaurene oxidase were among the top 20 most highly expressed, but the significance for regulating the biosynthesis of aconitine remains unknown. Additionally, unigenes annotated as GGPPS and CDPS were highly expressed in A. carmichaelii leaf tissue [13], consistent with GGPPS but not CDPS in the present work. Several studies report that CDPS is involved in tissue-specific accumulation of DAs [30, 31], but the reason for the low expression of CDPS observed in the present work needs to be further explored.

Salsolinol was detected in both Z175 and R184, and at a higher concentration in Z175. Salsolinol biosynthesis in A. carmichaelii is derived from the biosynthesis of alkaloids generated by glycolysis (map00010), the shikimate pathway, phenylalanine, tyrosine, and tryptophan biosynthesis (map00400) and isoquinoline alkaloid biosynthesis (map00950). In the salsolinol biosynthesis pathway, genes encoding enzymes related to glycolysis were the most highly expressed, followed by shikimate and chorismate pathway genes.

The glycolysis pathway and its enzymes convert glucose to pyruvic acid using the oxidative potential of NAD+, and this pathway is among the most ancient molecular metabolic networks [32]. In glycolysis, glucose is converted to phosphoenolpyruvate (PEP) by eight central glycolysis enzymes. This was the most well-represented biological process, with one PGAM, 19 HK, 13 GPI, 30 PFK, 31 ALDO, nine GAPHD, 32 PGK and 23 ENO enzymes, and six unigenes were highly expressed in Z175, along with four in R184, while 7/31 ALDO, 6/32 PGK, 2/23 ENO, 1/19 HK, 2/13 GPI, 1/9 GAPHD and 1/30 PFK genes were among the top 20 most highly expressed enzymes related to glycolysis. Most previous studies related to the biosynthesis of C19-diterpenoid alkaloids indicated changes in the abundance of enzymes involved in carbohydrate metabolism in plants under abiotic stress. Specifically, expression of enzymes catalyzing steps in glycolysis such as GAPDH, PGK and PGM, and especially ENO are upregulated [33]. In the case of ENO, this occurs in both the cytoplasm, where it functions as a key glycolytic enzyme, and in plastids which have their own glycolytic pathway [34]. Glycolytic enzymes have acquired additional nonglycolytic functions, as exemplified by HK, GAPHD and ENO, which function in transcriptional regulation, while glucose-6-phosphate isomerase (GPI) functions in the stimulation of cell motility, and HK and GAPHD regulate apoptosis [35].

The shikimate pathway is the key process by which aromatic amino acids are synthesized, and it is also important for salsolinol biosynthesis. Aromatic amino acids are synthesized via the shikimate pathway followed by the branched aromatic amino acid metabolic pathway, with chorismate serving as a major branch point intermediate metabolite [36]. The conversion of PEP and erythrose-4P to chorismate comprises seven reactions catalyzed by six enzymes in the shikimate pathway. Herein, 22 AROF, two AROB, nine AROD/AROE, 13 AROK, two AROA and 27 AROC enzymes were linked to the shikimate pathway, with five unigenes more highly expressed in Z175 and one more highly expressed in R184. All AROB, 9/22 AROF, 1/2 AROA, 3/27 AROC, 3/13 AROK and 2/9 AROD/AROE were in the top 20 most highly expressed among all enzymes in the shikimate pathway. AROF activity may be central to the ability of the shikimate pathway to compete for PEP and erythrose-4P with glycolysis and the non-oxidative pentose phosphate pathway [36]. Thus, high expression of aroF may be conducive to successful salsolinol biosynthesis. Indeed, aroF genes were abundant among the identified unigenes (22), and all four unigenes in Z175 were highly expressed, consistent with higher salsolinol content in Z175 than R184, and any of these four DEGs can be selected as target genes. AROB, the second enzyme in this pathway, converts 3-deoxy-d-arabino-heptulosonate-7-phosphate into 3-dehydroquinate, both of which are highly expressed in $A$. carmichaelii. The actions of AROD/AROE lead to shikimate, bifunctional activity has been characterized in Solanum lycopersicum [37], and the crystal structure of the Arabidopsis enzyme with shikimate bound at the AROE site and tartrate at the AROD site has recently been elucidated [38]. The enzyme encoded by AROK converts shikimate to shikimate 3-phosphate. Interestingly, Oryza sativa AROK genes are differentially expressed in specific developmental stages and in response to biotic stress [39], and plant AROK activity is sensitive to changes in cellular ATP, suggesting that plant AROK acts as a regulatory factor in the shikimate pathway, facilitating metabolic flux toward specific pools of secondary metabolites [36]. The activity of AROA leads to the synthesis of enolpyruvylshikimate-3-phosphate (EPSP), and AROC converts EPSP to chorismate.

In chorismate pathway, there are seven CHMU, five PAT, seven TYRC, 23 POX and six TYDC enzymes that complete the biosynthesis route of salsolinol(Fig. 5) of which 14/23 POX, 2/5 PAT, 1/7 CHMU and 1/6 TYDC enzymes were in the top 20 most highly expressed. The major biosynthetic route for phenylalanine in plants proceeds via arogenate [36]. CHMU converts chorismate to prephenate, and prephenate is then transaminated to arogenate, which is subsequently converted to tyrosine by TYRC $[40,41]$. Tyrosine is synthesized de novo in plants via two alternative routes mediated by a TyrA family enzyme and prephenate in the shikimate pathway [42], and intermediates serve as precursors of a wide range of secondary metabolites [40]. The tyrosinase activity of POX is believed to be the key factor mediating the initial L-DOPA conversion [43]. Many studies demonstrate a correlation between POX and metabolism, such as betalain pigment formation [44]. In A. carmichaelii, POX enzymes are abundant (23), and all seven unigenes are highly expressed in Z175, consistent with the higher salsolinol content in Z175 than R184, and all seven DEGs can be selected as target genes. Dopamine is derived from L-Dopa by tyrosine decarboxylase [45].

Interestingly, coryneine chloride, which is functionally equivalent as salsolinol[46], was isolated from $A$. carmichaelii in 1979, and the tethrahydroisoquinoline salsolinol is present in banana and biosynthesized from dopamine [47], further rationalizing salsolinol biosynthesis in A. carmichaelii. However, it remains unclear how dopamine biosynthesis is linked to salsolinol in A. carmichaelii. In the mammalian brain, salsolinol can be enzymatically synthesized by salsolinol synthase from dopamine and acetaldehyde, but direct evidence of its biosynthesis is still lacking [48]. Synthesis can occur nonenzymatically as mentioned above. Thus, biosynthesis of salsolinol is not completely understood, although it is known to be derived from dopamine or L-Dopa.

\section{Conclusions}

A total of 281 unigenes were identified as potentially involved in the salsolinol biosynthetic pathway in A. carmichaelii, with 24 DEGs between Z175 and R184 varieties, including 158 in glycolysis and 75 in the shikimate pathway. A total of 843 candidate unigenes were predicted to be involved in the formation of C19-diterpenoid alkaloids, with 34 DEGs between Z175 and R184. The transcriptome data showed that genes involved in alkaloid biosynthesis are differentially expressed in different varieties, consistent with differences in the accumulation of alkaloids. This expands our understanding of alkaloids, provides a foundation for future research into the molecular basis of aconitine-type C19-DAs and salsolinol biosynthesis, and sheds light on the synthesis of these acutely toxic components of Aconitum. 


\section{Methods}

\section{Plant Materials}

A. carmichaelii plants (plant material is two varieties Z175 and R184) were grown in natural conditions at Jiangyou Fuzi GAP cultivation base and were identified by Guangming Shu, a researcher of Sichuan academy of traditional Chinese medicine sciences. And the voucher specimens of this material have been deposited in the herbarium of Sichuan academy of traditional Chinese medicine sciences. The leafs were harvested on ice in the month of September 2016 and snap frozen using liquid nitrogen. Then all samples were taken back indoor and stored at $-80^{\circ} \mathrm{C}$ for RNA extraction.

\section{RNA Isolation, cDNA Library Preparation and Illumina Sequencing.}

Total RNA was extracted from A. carmichaelii leafs using TRIzol reagent (Ambion) and the RNeasy Plus Mini Kit (No. 74134; Qiagen, Hilden, Germany) following the manufacturer's instructions. RNA quantity was $d$ was monitored on $1 \%$ agarose gels. RNA concentration was measured using Qubit ${ }^{8}$ RNA Assay Kit in Qubit 2.0 Flurometer (Life Technologies, CA, USA). RNA of Z175 and R184 A. carmichaelii leafs with three biological duplication were used to construct the cDNA library respectively. cDNA library construction and Illumina sequencing of samples were performed at GenexHealth Corporation (Beijing, China). mRNA samples were purified and fragmented using the NEBNext Ultra ${ }^{\text {TM }}$ RNA Library Prep Kit for Illumina ${ }^{\circledR}$ (NEB, USA). Random hexamer primers were used to synthesize the first-strand cDNA, followed by synthesis of the second-strand cDNA using buffer, dNTPs, RNase $\mathrm{H}$, and DNA polymerase I at $16^{\circ} \mathrm{C}$ for $1 \mathrm{~h}$. After end repair, A-tailing, and the ligation of adaptors, the products were amplified by PCR and quantified precisely using the Qubit DNA Br Assay Kit (Q10211; Invitrogen, Carlsbad, CA, USA). They were then purified in AMPure XP system (Beckman Coulter, Beverly, USA) to obtain a cDNA library, and library quality was assessed on the Agilent Bioanalyzer 2100 system(Agilent Technologies, CA, USA). The cDNA library was sequenced on the HiSeq2500 platform in GenexHealth, Ltd., Beijing, China.

\section{Assembly and functional annotation}

All raw reads were processed to remove low-quality and adaptor sequences by Trimmomatic (http://www.usadellab.org/cms/index.php?page=trimmomatic). Transcriptome assembly was accomplished based on the claen reads using Trinity [49] with min_kmer_cov set to 2 by default and all other parameters set default after combined the six leafs clean reads. The largest alternative splicing variants in the Trinity results were called unigenes. The transcription factor (TF) encoding transcripts were identified based on similarity search against Plant Transcription Factor Database (http://planttfdb.cbi.pku.edu.cn). The annotation of unigenes was in seven databases which include NCBI non-redundant protein sequences (Nr), NCBI nucleotide sequences (Nt), Protein family (Pfam), Clusters of Orthologous Groups of proteins/euKaryotic Ortholog Groups (COG/KOG), Swiss-Prot, Kyoto Encyclopedia of Genes and Genomes (KEGG), and Gene Ontology (GO).For the putative protein sequences, we performed blastx search against the Nt database (https://www.ncbi.nlm.nih.gov/nuccore) with an E value cut-off of 1.0E-5. Nr database (http://www.ncbi.nlm.nih.gov/genbank/) and Swiss-Prot (http://www. uniprot.org/) were searched by diamond v0.8.22[50] with an E value cut-off of 1.0E-5, Clusters of Orthologous Groups of proteins/euKaryotic Ortholog Groups (COG /KOG) with E value cut-off of 1.0E3. Pfam (http://pfam.sanger.ac.uk/) were searched by HMMER 3.0 package[51] with e-value $=0.01$. BLAST2GO was used to obtain Gene Ontology (GO) annotation of assembled unigenes for describing cellular component, molecular function, and biological process with an E value cut-off of 1.0E-6[52]. Unigenes were searched in KEGG database (http:// www.genome.jp/kegg/pathway.html)with BLAST at $E$ values $\leq 1 e-10$. Expression levels were expressed in terms of FPKM values (fragments per kilobase per million reads)[53], which was calculated by RSEM (RNA-Seq by Expectation-Maximization)(Version: v1.2.6)with default parameters[54]. For the three biological replicates, differential expression analysis of two breed sample(Z175 and R184) was performed using the DESeq R package (1.10.1), and genes with an a log2 fold-change of $>1$ and pdaj $<0.05$ found by DESeq were assigned as differentially expressed[55]. Gene Ontology (GO) enrichment analysis of the differentially expressed genes (DEGs) was implemented by the GOseq R packages based Wallenius non-central hyper-geometric distribution[56], which can adjust for gene length bias in DEGs. We used KOBAS [57] software to test the statistical enrichment of differential expression genes in KEGG pathways.

\section{List Of Abbreviations Used}

TCM: Chinese medicine, DA: diterpene alkaloids, MVA: mevalonate pathway, MEP: methylerythritol pathway, CPS: ent-CPP synthases, KS: ent-kaurene synthases, KOX: kaurene oxidases, TFs: transcription factors, nr: NCBI non-redundant, Nt: NCBI nucleotide sequences, Pfam: protein family, KOG: Clusters of euKaryotic Ortholog Groups, COG: Clusters of Orthologous Groups of proteins, GO: Gene Ontology, KEGG: Kyoto Encyclopedia of Genes and Genomes, DEGs: differential expressed genes, DXS: 1-deoxy-D-xylulose 5-phosphatesynthase, DXR: 1-deoxy-D-xylulose 5-phosphate reductoisomerase, ISPD: 2-C-methyl-Derythritol 4-phosphate cytidylyltransferase, ISPE: 4-(cytidine- 50-diphospho)-2-C-methyl-D-erythritol kinase, ISPF: 2-C- methyl-D-erythritol2,4 -cyclodiphosphate synthase, ISPG: (E)-4-hydroxy-3- methylbut-2-enyldiphosphate synthase, ISPH: (E)-4-hydroxy-3-methylbut-2-enyl diphosphate reductase, IPPI: isopentenyl diphosphate isomerase, AACT: acetoacetyl-CoA thiolase, HMGR: 3-hydroxy-3-methylglutaryl- CoA reductase, HMGS: 3-hydroxy-3-methylglutaryl- CoA synthase, MVK: mevalonate kinase, PMK: phosphomevalonate kinase, MVDD: mevalonate diphosphate decarboxylase, GGPPS: geranylgeranyl pyrophosphate synthase, CPS: ent-copalyl diphosphate synthase, KS: entkaurene synthases, HK: he xokinase, GPI: glucose-6-phosphate isomerase, PFK: 6phosphofructokinase, ALDO: fructose-bisphosphate aldolase, GAPHD: glyceraldehyde 3-phosphate dehydrogenase, PGK: phosphoglycerate kinase, PGAM: 2,3-bisphosphoglycerate-dependent phosphoglycerate mutase, ENO: enolase, aroF: phospho-2-dehydro-3- deoxyheptonate aldolase, AROB: 3-dehydroquinate synthase, AROD/AROE: 3-dehydroquinate/shikimate dehydratase, AROK: shikimate kinase, AROA: 3-phosphoshikimate 1-carboxyvinyltransferase, AROC: chorismate synthase, CHMU: chorismate mutase, PAT: bifunctional aspartate aminotransferase and glutamate, TYRC : prephenate dehydrogenase, POX: polyphenol oxidase, TYDC: tyrosine decarboxylase

\section{Declarations}


Ethics approval and consent to participate

It is not applicable.

Consent for publication

It is not applicable.

Availability of data and material

All supporting data is included within the article and its additional files.

Competing interests

No competing interests and financial competing interests.

Funding

This work was supported by the National key R \& D Program (Grant No.2017YFC1701802 and 2017YFC1700700), the National Chinese Medicine Standardization Project (Grant No. ZYBZH-Y-ZY-45), the Sichuan Provincial Science and Technology Bureau breeding Program (Grant No. 2016NYZ0036), the Sichuan Science and Technology Bureau Science and Technology support Program (Grant No. 2015SZ0034) and Support of Science and Technology Poverty Alleviation Program of Sichuan Science and Technology Bureau (Grant No.2018NFP0053). The funders had no role in study design, data collection and analysis, decision to publish, or preparation of the manuscript.

\section{Authors' contributions}

Yuxia Yang carried out the molecular genetic studies, performed the sequence alignment, experiments and drafted the manuscript. Xianjian Zhou and Ping Wu collected almost all samples and participated in some experiments. Yanli Xia participated in all experiments. Ping Hu, Xinxin Si and Yanxi Zhu designed and conceived of the study; Bo Lu also helped to draft the manuscript. All authors read and approved the final manuscript.

\section{Acknowledgements}

We thanks for the workers in Jiangyou Fuzi GAP cultivation base in Sichuan province of China for cultivation two varieties.

\section{References}

1. Ma L, Gu R, Tang L, Chen Z-E, Di R, Long C: Important poisonous plants in Tibetan ethnomedicine. Toxins 2015, 7(1):138-155.

2. Li LQ, Kadota, Y., : Aconitum. In: Wu, ZY, Raven, P (Eds), Flora of China Science Press and Missouri Botanical Garden Press, Beijing; St Louis, 2001., pp:149222.

3. Wang X, Li X, Li L, Li M, Wu Q, Liu Y, Yang J, Jin Y: Green determination of aconitum alkaloids in Aconitum carmichaeli (Fuzi) by an ionic liquid aqueous two-phase system and recovery of the ionic liquid coupled with in situ liquid-liquid microextraction. Anal Methods 2016, 8(35):6566-6572.

4. Nyirimigabo E, Xu Y, Li Y, Wang Y, Agyemang K, Zhang Y: A review on phytochemistry, pharmacology and toxicology studies of Aconitum. J. Pharm Pharm $2015,67(1): 1-19$

5. Yu M, Yang Y-X, Shu X-Y, Huang J, Hou D-B: Aconitum carmichaelii Debeaux, cultivated as a medicinal plant in western China. Genetic resour crop ev 2016, 63(5):919-924.

6. Yu M, Cao L-L, Yang Y-X, Guan L-L, Gou L-L, Shu X-Y, Huang J, Liu D, Zhang H, Hou D-B: Genetic diversity and marker-trait association analysis for agronomic traits in Aconitum carmichaelii Debeaux. Biotechnol Biotec Eq 2017, 31(5):905-911.

7. Luo H, Huang Z, Tang X, Yi J, Chen S, Yang A, Yang J: Dynamic variation patterns of aconitum alkaloids in daughter root of Aconitum Carmichaelii (Fuzi) in the decoction process based on the content changes of nine Aconitum alkaloids by HPLC-MS-MS. Iran J pharm res: IJPR 2016, 15(1):263.

8. Wang FP, Liang, X.T., : C20-diterpenoid alkaloids. Alkaloids Chem Biol 2002, 59:1-280.

9. Zhou G, Tang L, Zhou X, Wang T, Kou Z, Wang Z: A review on phytochemistry and pharmacological activities of the processed lateral root of Aconitum carmichaelii Debeaux. J ethnopharm 2015, 160:173-193.

10. Zhao D, Shi Y, Zhu X, Liu L, Ji P, Long C, Shen Y, Kennelly EJ: Identification of potential biomarkers from Aconitum carmichaelii, a Traditional Chinese Medicine, using a metabolomic approach. Planta medica 2018, 84(06/07):434-441.

11. Weber M, Owens K, Sarpong R: Atropurpuran-missing biosynthetic link leading to the hetidine and arcutine C20-diterpenoid alkaloids or an oxidative degradation product? Tetrahedron lett 2015, 56(23):3600-3603. 
12. Singhuber J, Zhu M, Prinz S, Kopp B: Aconitum in traditional Chinese medicine-a valuable drug or an unpredictable risk? J ethnopharm 2009, 126(1):1830 .

13. Rai M, Rai A, Kawano N, Yoshimatsu K, Takahashi H, Suzuki H, Kawahara N, Saito K, Yamazaki M: De Novo RNA sequencing and expression analysis of Aconitum carmichaelii to analyze key genes involved in the biosynthesis of diterpene alkaloids. Molecules 2017, 22(12):2155.

14. Rai M, Rai A, Kawano N, Yoshimatsu K, Takahashi H, Suzuki H, Kawahara N, Saito K, Yamazaki M: De Novo RNA sequencing and expression analysis of Aconitum carmichaelii to analyze key genes involved in the biosynthesis of diterpene alkaloids. Molecules 2017, 22(12):2155.

15. Wang F-P, Chen Q-H: The C19-diterpenoid alkaloids. The Alkaloids: Chemistry and Biology 2010, 69:1-577.

16. Cherney EC, Baran PS: Terpenoid-Alkaloids: Their Biosynthetic Twist of Fate and Total Synthesis. Israel J chem 2011, 51(3-4):391-405.

17. Riggin RM, McCarthy MJ, Kissinger PT: Identification of salsolinol as a major dopamine metabolite in the banana. J agr food chem 1976, 24(1):189-191.

18. Whaley WM, Govindachari TR: The Pictet-S pengler Synthesis of Tetrahydroisoquinolines and Related Compounds. Organic reactions 1951, 6:151-190.

19. Chen X, Arshad A, Qing H, Wang R, Lu J, Deng Y: Enzymatic condensation of dopamine and acetaldehyde: a salsolinol synthase from rat brain. Biologia 2011, 66(6):1183.

20. Chen D-h, Hui-yin L, Song W-I: Study on the constituents of aconite from China(II),chemical composition of rhizoma cyperi. Chinese herbal medicine 1982, 3(11):481-483.

21. Zhao D, Shen Y, Shi Y, Shi X, Qiao Q, Zi S, Zhao E, Yu D, Kennelly EJ: Probing the transcriptome of Aconitum carmichaelii reveals the candidate genes associated with the biosynthesis of the toxic aconitine-type $C$ 19-diterpenoid alkaloids. Phytochem2018, 152:113-124.

22. Rohmer M: Mevalonate-independent methylerythritol phosphate pathway for isoprenoid biosynthesis. Elucidation and distribution. Pure Applied Chemy $2003,75(2-3): 375-388$

23. Jin J, Tian F, Yang D-C, Meng Y-Q, Kong L, Luo J, Gao G: PlantTFDB 4.0: toward a central hub for transcription factors and regulatory interactions in plants. Nucleic acids res 2016:gkw982.

24. Pal T, Malhotra N, Chanumolu SK, Chauhan RS: Next-generation sequencing (NGS) transcriptomes reveal association of multiple genes and pathways contributing to secondary metabolites accumulation in tuberous roots of Aconitum heterophyllum Wall. Planta 2015, 242(1):239-258.

25. Jørgensen K, Rasmussen AV, Morant M, Nielsen AH, Bjarnholt N, Zagrobelny M, Bak S, Møller BL: Metabolon formation and metabolic channeling in the biosynthesis of plant natural products. Curr opin plant biol 2005, 8(3):280-291.

26. Winkel BS: Metabolic channeling in plants. Annu Rev Plant Bio/ 2004, 55:85-107.

27. Tholl D, Lee S: Terpene specialized metabolism in Arabidopsis thaliana. The Arabidopsis Book/American Society of Plant Biologists $2011,9$.

28. Tholl D, Chen F, Petri J, Gershenzon J, Pichersky E: Two sesquiterpene synthases are responsible for the complex mixture of sesquiterpenes emitted from Arabidopsis flowers. The Plant Journal 2005, 42(5):757-771.

29. Dudareva N, Negre F, Nagegowda DA, Orlova I: Plant volatiles: recent advances and future perspectives. Crit rev plant sci 2006, 25(5):417-440.

30. Misra RC, Garg A, Roy S, Chanotiya CS, Vasudev PG, Ghosh S: Involvement of an ent-copalyl diphosphate synthase in tissue-specific accumulation of specialized diterpenes in Andrographis paniculata. Plant Sci 2015, 240:50-64.

31. Garg A, Agrawal L, Misra RC, Sharma S, Ghosh S: Andrographis paniculata transcriptome provides molecular insights into tissue-specific accumulation of medicinal diterpenes. BMC genomics 2015, 16(1):659.

32. Canback B, Andersson S, Kurland C: The global phylogeny of glycolytic enzymes. P Nati Acad Sci 2002, 99(9):6097-6102.

33. Kosová K, Vítámvás P, Prášil IT, Renaut J: Plant proteome changes under abiotic stress-contribution of proteomics studies to understanding plant stress response. J prot 2011, 74(8):1301-1322.

34. Lee H, Guo Y, Ohta M, Xiong L, Stevenson B, Zhu JK: LOS2, a genetic locus required for cold-responsive gene transcription encodes a bi-functional enolase. EMBO J 2002, 21(11):2692-2702.

35. Kim J-w, Dang CV: Multifaceted roles of glycolytic enzymes. Trends biochemi sci 2005, 30(3):142-150.

36. Tzin V, Galili G: The biosynthetic pathways for shikimate and aromatic amino acids in Arabidopsis thaliana. The Arabidopsis book/American Society of Plant Biologists 2010, 8.

37. Bischoff M, Schaller A, Bieri F, Kessler F, Amrhein N, Schmid J: Molecular characterization of tomato 3-dehydroquinate dehydratase-shikimate: NADP oxidoreductase. Plant Physi 2001, 125(4):1891-1900. 
38. Singh SA, Christendat D: Structure of Arabidopsis dehydroquinate dehydratase-shikimate dehydrogenase and implications for metabolic channeling in the shikimate pathway. Biochemi 2006, 45(25):7787-7796.

39. Kasai K, Kanno T, Akita M, Ikejiri-Kanno Y, Wakasa K, Tozawa Y: Identification of three shikimate kinase genes in rice: characterization of their differential expression during panicle development and of the enzymatic activities of the encoded proteins. Planta 2005, 222(3):438-447.

40. Maeda H, Dudareva N: The Shikimate Pathway and Aromatic Amino Acid Biosynthesis in Plants. Annu Rev Plant Bio/ 2012, $63(1): 73$.

41. Wen W, Jin M, Li K, Liu H, Xiao Y, Zhao M, Alseekh S, Li W, De AELF, Brotman Y: An Integrated Multi-layered Analysis of the Metabolic Networks of Different Tissues Uncovers Key Genetic Components of Primary Metabolism in Maize. Plant J Cell Mole Biol 2018.

42. Han Q, Phillips RS, Li. J: Aromatic Amino Acid Metabolism. Front Mole Biosci 2019, 6(22).

43. Sullivan ML: Beyond brown: polyphenol oxidases as enzymes of plant specialized metabolism. Front Plant Sci $2015,5: 783$.

44. Gao ZJ, Han XH, Xiao XG: Purification and characterisation of polyphenol oxidase from red Swiss chard (Beta vulgaris subspecies cicla ) leaves. Food Chemi 2009, 117(2):342-348.

45. Zhou Y, Wang X, Wang W, Duan H: De novo transcriptome sequencing-based discovery and expression analyses of verbascoside biosynthesis-associated genes in Rehmannia glutinosa tuberous roots. Mole Breeding 2016, 36(10):139.

46. Konno C, Shirasaka M, Hikino H: Cardioactive Principle of Aconitum carmichaeli Roots1. Planta medica 1979, 35(02):150-155.

47. Sojo MM, Nuñez-Delicado E, Sánchez-Ferrer A, García-Carmona F: Oxidation of salsolinol by banana pulp polyphenol oxidase and its kinetic synergism with dopamine. J agr food chemi 2000, 48(11):5543-5547.

48. Chen X, Zheng X, Ali S, Guo M, Zhong R, Chen Z, Zhang Y, Qing H, Deng Y: Isolation and Sequencing of Salsolinol Synthase, an Enzyme Catalyzing Salsolinol Biosynthesis. ACS chemi neurosci 2018, 9(6):1388-1398.

49. Grabherr M G HBJ, Yassour M , et al. : Full-length transcriptome assembly from RNA-Seq data without a reference genome. Nature Biotech 2011, 29(7):644-652.

50. Buchfink B XC, Huson D H . Fast and sensitive protein alignment using DIAMOND. Nature Methods 2015, 12(1):59-60.

51. Finn R D CJ, Eddy S R . Finn RD, Clements J, Eddy SR. : HMMER web server: interactive sequence similarity searching. Nucleic Acids Res 39: W29-W37. Nucleic Acids Research 2011, 39(Web Server issue):29-37.

52. Stefan Götz JMG, Terol J , et al.: High-throughput functional annotation and data mining with the Blast2GO suite. Nucleic Acids Research 2008, 36(10):3420-3435.

53. Mortazavi A WB, Mccue K, Schaeffer L, Wold B.: Mapping and quantifying mammalian transcriptomes by RNA-Seq. Nature Methods 2008, 5(7):621-628.

54. Li B DC: RSEM: accurate transcript quantification from RNA-Seq data with or without a reference genome. BMC Bioinform 2011, ,doi:10.1186/1471-210512-323.

55. M. I. Love WH, S Anders: Moderated estimation of fold change and dispersion for RNA-seq data with DESeq2. Genome Biology 2014, 15(doi:10.1186/s13059-014- 0550-8):550.

56. Young M D WMJ, Smyth G K, et al.: Gene ontology analysis for RNA-seq: accounting for selection bias. Genome Biology 2010( doi:10.1186/gb-2010-11-2r14.).

57. Mao X CT, Olyarchuk J G, et al. : Automated genome annotation and pathway identification using the KEGG Orthology (KO) as a controlled vocabulary. Bioinform 2005, 21:3787-3793.

\section{Tables}

Table 1 Unigenes involved in shikimat pathway of salsolinol biosynthesis pathway in A. carmichaelii. 


\begin{tabular}{|c|c|c|c|c|c|c|c|c|c|c|}
\hline Pathway & Enzyme & Enzyme name & Unigene & $\begin{array}{l}\text { Unigene } \\
\text { length }\end{array}$ & $\begin{array}{l}\text { NR } \\
\text { Evalue }\end{array}$ & $\begin{array}{l}\mathrm{Z} 175 \\
\text { readcount }\end{array}$ & $\begin{array}{l}\mathrm{R} 184 \\
\text { readcount }\end{array}$ & $\begin{array}{l}\text { Log2 } \\
\text { Fold } \\
\text { Change }\end{array}$ & Padj & Significant \\
\hline \multirow[t]{28}{*}{ shikimate } & AROF (22) & $\begin{array}{l}\text { phospho-2-dehydro-3- } \\
\text { deoxyheptonate aldolase }\end{array}$ & $\begin{array}{l}\text { Cluster- } \\
219.70422\end{array}$ & 1416 & $\begin{array}{l}2.20 \mathrm{E}- \\
189\end{array}$ & 987.779 & 586.544 & 0.754 & 0.129 & FALSE \\
\hline & & & $\begin{array}{l}\text { Cluster- } \\
219.50402\end{array}$ & 997 & $\begin{array}{l}3.50 \mathrm{E}- \\
138\end{array}$ & 24.846 & 0.000 & 6.989 & 0.000 & TRUE \\
\hline & & & $\begin{array}{l}\text { Cluster- } \\
219.76376\end{array}$ & 1448 & $\begin{array}{l}7.50 \mathrm{E}- \\
222\end{array}$ & 1094.075 & 642.408 & 0.764 & 0.595 & FALSE \\
\hline & & & $\begin{array}{l}\text { Cluster- } \\
219.4979\end{array}$ & 682 & $\begin{array}{l}1.50 \mathrm{E}- \\
68\end{array}$ & 30.730 & 0.000 & 7.293 & 0.000 & TRUE \\
\hline & & & $\begin{array}{l}\text { Cluster- } \\
219.85919\end{array}$ & 905 & $\begin{array}{l}1.10 \mathrm{E}- \\
24\end{array}$ & 8.002 & 2.799 & 1.479 & 0.986 & FALSE \\
\hline & & & $\begin{array}{l}\text { Cluster- } \\
219.76377\end{array}$ & 1065 & $\begin{array}{l}1.80 \mathrm{E}- \\
23\end{array}$ & 40.305 & 49.895 & -0.278 & 0.986 & FALSE \\
\hline & & & $\begin{array}{l}\text { Cluster- } \\
219.95746\end{array}$ & 1596 & $\begin{array}{l}3.20 \mathrm{E}- \\
189\end{array}$ & 136.163 & 50.428 & 1.393 & 0.034 & TRUE \\
\hline & & & $\begin{array}{l}\text { Cluster- } \\
219.66942\end{array}$ & 2214 & $\begin{array}{l}2.30 \mathrm{E}- \\
177\end{array}$ & 1083.541 & 702.647 & 0.627 & 0.170 & FALSE \\
\hline & & & $\begin{array}{l}\text { Cluster- } \\
219.68452\end{array}$ & 2244 & $\begin{array}{l}2.30 \mathrm{E}- \\
177\end{array}$ & 290.738 & 147.412 & 0.996 & 0.126 & FALSE \\
\hline & & & $\begin{array}{l}\text { Cluster- } \\
219.90735\end{array}$ & 795 & $\begin{array}{l}1.50 \mathrm{E}- \\
91\end{array}$ & 20.197 & 11.820 & 0.861 & 0.898 & FALSE \\
\hline & & & $\begin{array}{l}\text { Cluster- } \\
219.90734\end{array}$ & 777 & $\begin{array}{l}6.60 \mathrm{E}- \\
31\end{array}$ & 3.628 & 2.678 & 0.571 & 0.986 & FALSE \\
\hline & & & $\begin{array}{l}\text { Cluster- } \\
219.90736\end{array}$ & 514 & $\begin{array}{l}1.50 \mathrm{E}- \\
84\end{array}$ & 14.424 & 12.661 & 0.173 & 0.986 & FALSE \\
\hline & & & $\begin{array}{l}\text { Cluster- } \\
219.90731\end{array}$ & 373 & $\begin{array}{l}4.80 \mathrm{E}- \\
56\end{array}$ & 0.364 & 2.484 & -2.974 & 0.771 & FALSE \\
\hline & & & $\begin{array}{l}\text { Cluster- } \\
219.90733\end{array}$ & 410 & $\begin{array}{l}7.90 \mathrm{E}- \\
68\end{array}$ & 7.943 & 4.459 & 0.840 & 0.986 & FALSE \\
\hline & & & $\begin{array}{l}\text { Cluster- } \\
219.78492\end{array}$ & 1449 & $\begin{array}{l}1.10 \mathrm{E}- \\
143\end{array}$ & 148.295 & 6.287 & 4.434 & 0.000 & TRUE \\
\hline & & & $\begin{array}{l}\text { Cluster- } \\
219.78493\end{array}$ & 1123 & $\begin{array}{l}6.30 \mathrm{E}- \\
152\end{array}$ & 442.821 & 7.578 & 5.910 & 0.000 & TRUE \\
\hline & & & $\begin{array}{l}\text { Cluster- } \\
219.55023\end{array}$ & 1625 & $\begin{array}{l}1.20 \mathrm{E}- \\
143\end{array}$ & 12.687 & 5.843 & 1.132 & 0.901 & FALSE \\
\hline & & & $\begin{array}{l}\text { Cluster- } \\
219.76378\end{array}$ & 1648 & $\begin{array}{l}1.20 \mathrm{E}- \\
143\end{array}$ & 5.741 & 7.624 & -0.418 & 0.986 & FALSE \\
\hline & & & $\begin{array}{l}\text { Cluster- } \\
219.76379\end{array}$ & 940 & $\begin{array}{l}1.10 \mathrm{E}- \\
24\end{array}$ & 35.417 & 8.814 & 1.964 & 0.064 & FALSE \\
\hline & & & $\begin{array}{l}\text { Cluster- } \\
219.76371\end{array}$ & 1474 & $\begin{array}{l}1.60 \mathrm{E}- \\
219\end{array}$ & 932.282 & 286.674 & 1.695 & 0.069 & FALSE \\
\hline & & & $\begin{array}{l}\text { Cluster- } \\
219.76375\end{array}$ & 1163 & $\begin{array}{l}7.00 \mathrm{E}- \\
170\end{array}$ & 532.506 & 395.147 & 0.425 & 0.986 & FALSE \\
\hline & & & $\begin{array}{l}\text { Cluster- } \\
219.78348\end{array}$ & 481 & $\begin{array}{l}1.60 \mathrm{E}- \\
19\end{array}$ & 2.304 & 2.941 & -0.142 & 0.993 & FALSE \\
\hline & AROB (2) & $\begin{array}{l}\text { 3-dehydroquinate } \\
\text { synthase }\end{array}$ & $\begin{array}{l}\text { Cluster- } \\
219.68567\end{array}$ & 1576 & $\begin{array}{l}1.00 \mathrm{E}- \\
171\end{array}$ & 293.621 & 297.835 & -0.027 & 0.995 & FALSE \\
\hline & & & $\begin{array}{l}\text { Cluster- } \\
219.58881\end{array}$ & 1586 & $\begin{array}{l}1.00 \mathrm{E}- \\
171\end{array}$ & 1178.676 & 1136.651 & 0.050 & 0.986 & FALSE \\
\hline & $\begin{array}{l}\text { AROD/AROE } \\
\text { (9) }\end{array}$ & $\begin{array}{l}\text { 3- } \\
\text { dehydroquinate/shikimate } \\
\text { dehydratase }\end{array}$ & $\begin{array}{l}\text { Cluster- } \\
219.31617\end{array}$ & 622 & $\begin{array}{l}1.70 \mathrm{E}- \\
37\end{array}$ & 20.136 & 16.458 & 0.230 & 0.986 & FALSE \\
\hline & & & $\begin{array}{l}\text { Cluster- } \\
219.98650\end{array}$ & 631 & $\begin{array}{l}2.40 \mathrm{E}- \\
39\end{array}$ & 26.939 & 32.203 & -0.295 & 0.986 & FALSE \\
\hline & & & $\begin{array}{l}\text { Cluster- } \\
219.117612\end{array}$ & 855 & $\begin{array}{l}2.20 \mathrm{E}- \\
112\end{array}$ & 135.940 & 171.138 & -0.347 & 0.976 & FALSE \\
\hline & & & $\begin{array}{l}\text { Cluster- } \\
219.115502\end{array}$ & 634 & $\begin{array}{l}8.80 \mathrm{E}- \\
18\end{array}$ & 3.661 & 13.785 & -1.901 & 0.727 & FALSE \\
\hline
\end{tabular}




\begin{tabular}{|c|c|c|c|c|c|c|c|c|c|}
\hline & & $\begin{array}{l}\text { Cluster- } \\
219.111892\end{array}$ & 828 & $\begin{array}{l}1.80 \mathrm{E}- \\
103\end{array}$ & 67.842 & 90.047 & -0.424 & 0.986 & FALSE \\
\hline & & $\begin{array}{l}\text { Cluster- } \\
219.44644\end{array}$ & 1785 & $\begin{array}{l}1.10 \mathrm{E}- \\
185\end{array}$ & 80.404 & 57.276 & 0.494 & 0.975 & FALSE \\
\hline & & $\begin{array}{l}\text { Cluster- } \\
219.53108\end{array}$ & 1767 & $\begin{array}{l}1.10 \mathrm{E}- \\
185\end{array}$ & 366.201 & 561.737 & -0.623 & 0.595 & FALSE \\
\hline & & $\begin{array}{l}\text { Cluster- } \\
219.53107\end{array}$ & 628 & $\begin{array}{l}1.30 \mathrm{E}- \\
37\end{array}$ & 22.827 & 39.310 & -0.813 & 0.904 & FALSE \\
\hline & & $\begin{array}{l}\text { Cluster- } \\
219.120274\end{array}$ & 628 & $\begin{array}{l}3.40 \mathrm{E}- \\
38\end{array}$ & 7.130 & 3.130 & 1.106 & 0.986 & FALSE \\
\hline \multirow[t]{13}{*}{ AROK (13) } & shikimate kinase & $\begin{array}{l}\text { Cluster- } \\
219.96711\end{array}$ & 548 & $\begin{array}{l}4.30 \mathrm{E}- \\
21\end{array}$ & 23.179 & 46.764 & -0.978 & 0.631 & FALSE \\
\hline & & $\begin{array}{l}\text { Cluster- } \\
219.75068\end{array}$ & 1254 & $\begin{array}{l}8.20 \mathrm{E}- \\
92\end{array}$ & 533.148 & 439.217 & 0.278 & 0.956 & FALSE \\
\hline & & $\begin{array}{l}\text { Cluster- } \\
219.48198\end{array}$ & 929 & $\begin{array}{l}5.00 \mathrm{E}- \\
70\end{array}$ & 3.093 & 2.221 & 0.337 & 0.986 & FALSE \\
\hline & & $\begin{array}{l}\text { Cluster- } \\
219.48197\end{array}$ & 1043 & $\begin{array}{l}1.90 \mathrm{E}- \\
86\end{array}$ & 39.457 & 32.860 & 0.275 & 0.986 & FALSE \\
\hline & & $\begin{array}{l}\text { Cluster- } \\
219.49998\end{array}$ & 585 & $\begin{array}{l}2.60 \mathrm{E}- \\
16\end{array}$ & 5.737 & 7.671 & -0.469 & 0.986 & FALSE \\
\hline & & $\begin{array}{l}\text { Cluster- } \\
219.54689\end{array}$ & 1327 & $\begin{array}{l}1.10 \mathrm{E}- \\
91\end{array}$ & 0.000 & 17.765 & -6.746 & 0.001 & TRUE \\
\hline & & $\begin{array}{l}\text { Cluster- } \\
219.77462\end{array}$ & 1312 & $\begin{array}{l}8.60 \mathrm{E}- \\
92\end{array}$ & 409.405 & 70.477 & 2.560 & 0.000 & TRUE \\
\hline & & $\begin{array}{l}\text { Cluster- } \\
219.77463\end{array}$ & 492 & $\begin{array}{l}1.50 \mathrm{E}- \\
17\end{array}$ & 21.660 & 22.493 & -0.087 & 0.987 & FALSE \\
\hline & & $\begin{array}{l}\text { Cluster- } \\
219.42507\end{array}$ & 541 & $\begin{array}{l}5.40 \mathrm{E}- \\
16\end{array}$ & 1.091 & 1.721 & -0.698 & 0.986 & FALSE \\
\hline & & $\begin{array}{l}\text { Cluster- } \\
219.110751\end{array}$ & 537 & $\begin{array}{l}2.50 \mathrm{E}- \\
21\end{array}$ & 50.560 & 29.478 & 0.728 & 0.810 & FALSE \\
\hline & & $\begin{array}{l}\text { Cluster- } \\
219.106859\end{array}$ & 1473 & $\begin{array}{l}2.90 \mathrm{E}- \\
112\end{array}$ & 364.712 & 438.334 & -0.271 & 0.949 & FALSE \\
\hline & & $\begin{array}{l}\text { Cluster- } \\
219.50000\end{array}$ & 666 & $\begin{array}{l}7.70 \mathrm{E}- \\
12\end{array}$ & 20.422 & 22.756 & -0.215 & 0.986 & FALSE \\
\hline & & $\begin{array}{l}\text { Cluster- } \\
219.77461\end{array}$ & 1269 & $\begin{array}{l}1.10 \mathrm{E}- \\
91\end{array}$ & 3.039 & 151.252 & -5.580 & 0.000 & TRUE \\
\hline \multirow[t]{2}{*}{ AROA (2) } & $\begin{array}{l}\text { 3-phosphoshikimate 1- } \\
\text { carboxyvinyltransferase }\end{array}$ & $\begin{array}{l}\text { Cluster- } \\
219.53999\end{array}$ & 2137 & $\begin{array}{l}1.40 \mathrm{E}- \\
232\end{array}$ & 580.358 & 427.825 & 0.435 & 0.788 & FALSE \\
\hline & & $\begin{array}{l}\text { Cluster- } \\
219.54000\end{array}$ & 2136 & $\begin{array}{l}1.40 \mathrm{E}- \\
232\end{array}$ & 74.586 & 0.000 & 8.573 & 0.292 & FALSE \\
\hline \multirow[t]{10}{*}{ AROC (27) } & chorismate synthase & $\begin{array}{l}\text { Cluster- } \\
219.1696\end{array}$ & 1747 & $\begin{array}{l}3.00 \mathrm{E}- \\
217\end{array}$ & 3.175 & 0.482 & 2.353 & 0.859 & FALSE \\
\hline & & $\begin{array}{l}\text { Cluster- } \\
4218.0\end{array}$ & 1296 & $\begin{array}{l}4.10 \mathrm{E}- \\
54\end{array}$ & 3.812 & 2.785 & 0.373 & 0.986 & FALSE \\
\hline & & $\begin{array}{l}\text { Cluster- } \\
219.70284\end{array}$ & 1401 & $\begin{array}{l}1.50 \mathrm{E}- \\
20\end{array}$ & 4.217 & 7.898 & -0.963 & 0.960 & FALSE \\
\hline & & $\begin{array}{l}\text { Cluster- } \\
18528.0\end{array}$ & 1157 & $\begin{array}{l}1.80 \mathrm{E}- \\
149\end{array}$ & 0.817 & 0.509 & 0.389 & 0.991 & FALSE \\
\hline & & $\begin{array}{l}\text { Cluster- } \\
219.72560\end{array}$ & 1866 & $\begin{array}{l}3.80 \mathrm{E}- \\
234\end{array}$ & 0.000 & 1.754 & -3.462 & 0.960 & FALSE \\
\hline & & $\begin{array}{l}\text { Cluster- } \\
219.2484\end{array}$ & 2287 & $\begin{array}{l}5.20 \mathrm{E}- \\
201\end{array}$ & 25.197 & 27.189 & -0.129 & 0.993 & FALSE \\
\hline & & $\begin{array}{l}\text { Cluster- } \\
16761.0\end{array}$ & 1204 & $\begin{array}{l}4.70 \mathrm{E}- \\
60\end{array}$ & 1.295 & 0.722 & 0.661 & 0.986 & FALSE \\
\hline & & $\begin{array}{l}\text { Cluster- } \\
219.127477\end{array}$ & 2389 & $\begin{array}{l}3.10 \mathrm{E}- \\
180\end{array}$ & 8.193 & 6.128 & 0.363 & 0.986 & FALSE \\
\hline & & $\begin{array}{l}\text { Cluster- } \\
219.127478\end{array}$ & 2309 & $\begin{array}{l}3.00 \mathrm{E}- \\
180\end{array}$ & 20.332 & 10.144 & 0.947 & 0.986 & FALSE \\
\hline & & Cluster- & $\begin{array}{l}2221 \\
\text { ge } 11 / 18\end{array}$ & $2.70 \mathrm{E}-$ & 52.510 & 60.627 & -0.208 & 0.986 & FALSE \\
\hline
\end{tabular}




\begin{tabular}{|c|c|c|c|c|c|c|c|}
\hline \multicolumn{2}{|l|}{219.127479} & \multicolumn{3}{|l|}{138} & \multirow[b]{2}{*}{-0.119} & \multirow[b]{2}{*}{0.986} & \multirow[b]{2}{*}{ FALSE } \\
\hline $\begin{array}{l}\text { Cluster- } \\
219.98159\end{array}$ & 1910 & $\begin{array}{l}2.50 \mathrm{E}- \\
140\end{array}$ & 12.405 & 13.315 & & & \\
\hline $\begin{array}{l}\text { Cluster- } \\
219.34273\end{array}$ & 1153 & $\begin{array}{l}3.60 \mathrm{E}- \\
110\end{array}$ & 42.996 & 46.746 & -0.100 & 0.986 & FALSE \\
\hline $\begin{array}{l}\text { Cluster- } \\
219.37391\end{array}$ & 1526 & $\begin{array}{l}2.00 \mathrm{E}- \\
172\end{array}$ & 77.856 & 51.714 & 0.562 & 0.966 & FALSE \\
\hline $\begin{array}{l}\text { Cluster- } \\
219.108691\end{array}$ & 498 & $\begin{array}{l}3.80 \mathrm{E}- \\
08\end{array}$ & 9.540 & 8.087 & 0.263 & 0.986 & FALSE \\
\hline $\begin{array}{l}\text { Cluster- } \\
219.127475\end{array}$ & 2207 & $\begin{array}{l}5.00 \mathrm{E}- \\
201\end{array}$ & 65.792 & 97.066 & -0.561 & 0.954 & FALSE \\
\hline $\begin{array}{l}\text { Cluster- } \\
219.139826\end{array}$ & 1230 & $\begin{array}{l}8.00 \mathrm{E}- \\
116\end{array}$ & 14.052 & 18.452 & -0.442 & 0.986 & FALSE \\
\hline $\begin{array}{l}\text { Cluster- } \\
219.103461\end{array}$ & 1164 & $\begin{array}{l}3.60 \mathrm{E}- \\
158\end{array}$ & 64.412 & 90.052 & -0.508 & 0.881 & FALSE \\
\hline $\begin{array}{l}\text { Cluster- } \\
219.103460\end{array}$ & 1412 & $\begin{array}{l}1.20 \mathrm{E}- \\
131\end{array}$ & 2.786 & 13.612 & -2.249 & 0.739 & FALSE \\
\hline $\begin{array}{l}\text { Cluster- } \\
219.56676\end{array}$ & 1592 & $\begin{array}{l}4.60 \mathrm{E}- \\
196\end{array}$ & 283.565 & 237.030 & 0.249 & 0.986 & FALSE \\
\hline $\begin{array}{l}\text { Cluster- } \\
219.92842\end{array}$ & 1708 & $\begin{array}{l}3.60 \mathrm{E}- \\
183\end{array}$ & 413.452 & 256.299 & 0.685 & 0.161 & FALSE \\
\hline $\begin{array}{l}\text { Cluster- } \\
219.130746\end{array}$ & 1237 & $\begin{array}{l}3.60 \mathrm{E}- \\
116\end{array}$ & 4.392 & 16.128 & -1.879 & 0.890 & FALSE \\
\hline $\begin{array}{l}\text { Cluster- } \\
219.103459\end{array}$ & 1380 & $\begin{array}{l}1.20 \mathrm{E}- \\
131\end{array}$ & 16.792 & 28.999 & -0.744 & 0.975 & FALSE \\
\hline $\begin{array}{l}\text { Cluster- } \\
219.103456\end{array}$ & 1567 & $\begin{array}{l}1.00 \mathrm{E}- \\
155\end{array}$ & 29.700 & 40.782 & -0.487 & 0.986 & FALSE \\
\hline $\begin{array}{l}\text { Cluster- } \\
219.103457\end{array}$ & 1534 & $\begin{array}{l}1.30 \mathrm{E}- \\
131\end{array}$ & 8.712 & 24.885 & -1.488 & 0.416 & FALSE \\
\hline $\begin{array}{l}\text { Cluster- } \\
219.103454\end{array}$ & 320 & $\begin{array}{l}4.20 \mathrm{E}- \\
24\end{array}$ & 1.455 & 0.254 & 1.890 & 0.986 & FALSE \\
\hline $\begin{array}{l}\text { Cluster- } \\
18286.0\end{array}$ & 1184 & $\begin{array}{l}4.40 \mathrm{E}- \\
111\end{array}$ & 4.167 & 6.664 & -0.706 & 0.986 & FALSE \\
\hline $\begin{array}{l}\text { Cluster- } \\
12929.0\end{array}$ & 1124 & $\begin{array}{l}2.60 \mathrm{E}- \\
60\end{array}$ & 0.364 & 0.763 & -1.422 & 0.986 & FALSE \\
\hline
\end{tabular}

Table 2 unigenes involved in of salsolinol biosynthesis pathway except glycolysis and shikimate pathway in A. carmichaelii. 


\begin{tabular}{|c|c|c|c|c|c|c|c|c|c|}
\hline Enzyme & Enzyme name & Unigene & $\begin{array}{l}\text { Unigene } \\
\text { length }\end{array}$ & $\begin{array}{l}\text { NR } \\
\text { Evalue }\end{array}$ & $\begin{array}{l}\mathrm{Z} 175 \\
\text { readcount }\end{array}$ & $\begin{array}{l}\mathrm{R} 184 \\
\text { readcount }\end{array}$ & $\begin{array}{l}\text { Log2 } \\
\text { FoldChange }\end{array}$ & Padj & Significant \\
\hline \multirow[t]{7}{*}{$\begin{array}{l}\text { CHMU } \\
\text { (7) }\end{array}$} & chorismate mutase & $\begin{array}{l}\text { Cluster- } \\
219.11902\end{array}$ & 584 & $\begin{array}{l}6.60 \mathrm{E}- \\
84\end{array}$ & 31.295 & 32.785 & -0.110 & 0.986 & FALSE \\
\hline & & $\begin{array}{l}\text { Cluster- } \\
219.82304\end{array}$ & 663 & $\begin{array}{l}8.60 \mathrm{E}- \\
72\end{array}$ & 25.876 & 17.853 & 0.487 & 0.986 & FALSE \\
\hline & & $\begin{array}{l}\text { Cluster- } \\
219.98270\end{array}$ & 1361 & $\begin{array}{l}3.00 \mathrm{E}- \\
111\end{array}$ & 36.949 & 19.476 & 0.893 & 0.986 & FALSE \\
\hline & & $\begin{array}{l}\text { Cluster- } \\
219.98271\end{array}$ & 1061 & $\begin{array}{l}5.70 \mathrm{E}- \\
78\end{array}$ & 0.253 & 2.758 & -3.170 & 0.850 & FALSE \\
\hline & & $\begin{array}{l}\text { Cluster- } \\
219.93045\end{array}$ & 1224 & $\begin{array}{l}8.30 \mathrm{E}- \\
113\end{array}$ & 572.847 & 651.924 & -0.188 & 0.976 & FALSE \\
\hline & & $\begin{array}{l}\text { Cluster- } \\
219.67054\end{array}$ & 1223 & $\begin{array}{l}2.70 \mathrm{E}- \\
111\end{array}$ & 57.315 & 82.108 & -0.522 & 0.874 & FALSE \\
\hline & & $\begin{array}{l}\text { Cluster- } \\
219.67055\end{array}$ & 674 & $\begin{array}{l}8.70 \mathrm{E}- \\
72\end{array}$ & 58.800 & 63.246 & -0.108 & 0.986 & FALSE \\
\hline \multirow[t]{5}{*}{ PAT ( 5) } & $\begin{array}{l}\text { bifunctional aspartate } \\
\text { aminotransferase and glutamate }\end{array}$ & $\begin{array}{l}\text { Cluster- } \\
219.109926\end{array}$ & 1821 & $\begin{array}{l}1.40 \mathrm{E}- \\
188\end{array}$ & 97.250 & 137.349 & -0.511 & 0.816 & FALSE \\
\hline & & $\begin{array}{l}\text { Cluster- } \\
219.109927\end{array}$ & 1786 & $\begin{array}{l}9.70 \mathrm{E}- \\
187\end{array}$ & 103.681 & 157.760 & -0.596 & 0.456 & FALSE \\
\hline & & $\begin{array}{l}\text { Cluster- } \\
219.139132\end{array}$ & 542 & $\begin{array}{l}5.10 \mathrm{E}- \\
30\end{array}$ & 4.756 & 11.616 & -1.270 & 0.696 & FALSE \\
\hline & & $\begin{array}{l}\text { Cluster- } \\
219.132472\end{array}$ & 698 & $\begin{array}{l}4.00 \mathrm{E}- \\
64\end{array}$ & 3.424 & 7.438 & -1.163 & 0.881 & FALSE \\
\hline & & $\begin{array}{l}\text { Cluster- } \\
219.132473\end{array}$ & 922 & $\begin{array}{l}2.50 \mathrm{E}- \\
98\end{array}$ & 8.772 & 5.868 & 0.499 & 0.986 & FALSE \\
\hline \multirow[t]{7}{*}{$\begin{array}{l}\text { TYRC ( } \\
\text { 7) }\end{array}$} & prephenate dehydrogenase & $\begin{array}{l}\text { Cluster- } \\
219.51852\end{array}$ & 2930 & $\begin{array}{l}5.90 \mathrm{E}- \\
16\end{array}$ & 2.893 & 0.990 & 1.352 & 0.986 & FALSE \\
\hline & & $\begin{array}{l}\text { Cluster- } \\
219.57952\end{array}$ & 2933 & $\begin{array}{l}5.90 \mathrm{E}- \\
16\end{array}$ & 3.743 & 3.441 & 0.177 & 0.990 & FALSE \\
\hline & & $\begin{array}{l}\text { Cluster- } \\
219.53953\end{array}$ & 3637 & $\begin{array}{l}7.40 \mathrm{E}- \\
16\end{array}$ & 31.361 & 14.272 & 1.140 & 0.975 & FALSE \\
\hline & & $\begin{array}{l}\text { Cluster- } \\
219.53947\end{array}$ & 3293 & $\begin{array}{l}1.90 \mathrm{E}- \\
15\end{array}$ & 19.069 & 51.736 & -1.414 & 0.073 & FALSE \\
\hline & & $\begin{array}{l}\text { Cluster- } \\
219.53946\end{array}$ & 3640 & $\begin{array}{l}7.40 \mathrm{E}- \\
16\end{array}$ & 48.228 & 38.448 & 0.337 & 0.986 & FALSE \\
\hline & & $\begin{array}{l}\text { Cluster- } \\
219.53942\end{array}$ & 3290 & $\begin{array}{l}1.90 \mathrm{E}- \\
15\end{array}$ & 13.222 & 24.050 & -0.895 & 0.872 & FALSE \\
\hline & & $\begin{array}{l}\text { Cluster- } \\
219.49397\end{array}$ & 345 & $\begin{array}{l}2.80 \mathrm{E}- \\
10\end{array}$ & 0.000 & 0.241 & -1.206 & 0.986 & FALSE \\
\hline \multirow[t]{10}{*}{$\begin{array}{l}\text { POX } \\
\text { (23) }\end{array}$} & polyphenol oxidase & $\begin{array}{l}\text { Cluster- } \\
219.54921\end{array}$ & 2241 & $\begin{array}{l}8.80 \mathrm{E}- \\
129\end{array}$ & 1513.885 & 63.678 & 4.570 & 0.140 & FALSE \\
\hline & & $\begin{array}{l}\text { Cluster- } \\
219.54923\end{array}$ & 1967 & $\begin{array}{l}6.00 \mathrm{E}- \\
113\end{array}$ & 72.495 & 16.046 & 2.126 & 0.347 & FALSE \\
\hline & & $\begin{array}{l}\text { Cluster- } \\
219.7282\end{array}$ & 570 & $\begin{array}{l}1.40 \mathrm{E}- \\
14\end{array}$ & 38.572 & 39.573 & -0.021 & 0.996 & FALSE \\
\hline & & $\begin{array}{l}\text { Cluster- } \\
219.55521\end{array}$ & 2226 & $\begin{array}{l}1.10 \mathrm{E}- \\
126\end{array}$ & 1562.077 & 246.422 & 2.663 & 0.798 & FALSE \\
\hline & & $\begin{array}{l}\text { Cluster- } \\
22607.0\end{array}$ & 827 & $\begin{array}{l}5.30 \mathrm{E}- \\
71\end{array}$ & 11.265 & 0.730 & 4.873 & 0.049 & TRUE \\
\hline & & $\begin{array}{l}\text { Cluster- } \\
219.77526\end{array}$ & 1984 & $\begin{array}{l}4.40 \mathrm{E}- \\
196\end{array}$ & 1700.704 & 1167.533 & 0.543 & 0.810 & FALSE \\
\hline & & $\begin{array}{l}\text { Cluster- } \\
219.14771\end{array}$ & 2019 & $\begin{array}{l}2.40 \mathrm{E}- \\
186\end{array}$ & 65.567 & 296.068 & -2.177 & 0.090 & FALSE \\
\hline & & $\begin{array}{l}\text { Cluster- } \\
24818.0\end{array}$ & 398 & $\begin{array}{l}9.20 \mathrm{E}- \\
13\end{array}$ & 5.627 & 0.509 & 3.136 & 0.584 & FALSE \\
\hline & & $\begin{array}{l}\text { Cluster- } \\
219.82880\end{array}$ & 1894 & $\begin{array}{l}1.80 \mathrm{E}- \\
106\end{array}$ & 136.438 & 21.852 & 2.647 & 0.045 & TRUE \\
\hline & & Cluster- & 1924 & 8.00E- & 18.972 & 70.761 & -1.908 & 0.467 & FALSE \\
\hline
\end{tabular}




\begin{tabular}{|c|c|c|c|c|c|c|c|c|}
\hline & \multicolumn{2}{|l|}{219.101914} & \multicolumn{4}{|l|}{187} & \multirow[b]{2}{*}{0.385} & \multirow[b]{2}{*}{ FALSE } \\
\hline & $\begin{array}{l}\text { Cluster- } \\
219.54919\end{array}$ & 2117 & $\begin{array}{l}2.40 \mathrm{E}- \\
104\end{array}$ & 434.744 & 79.363 & 2.446 & & \\
\hline & $\begin{array}{l}\text { Cluster- } \\
219.54918\end{array}$ & 2044 & $\begin{array}{l}3.90 \mathrm{E}- \\
123\end{array}$ & 1144.021 & 78.026 & 3.846 & 0.000 & TRUE \\
\hline & $\begin{array}{l}\text { Cluster- } \\
219.54917\end{array}$ & 2307 & $\begin{array}{l}1.80 \mathrm{E}- \\
116\end{array}$ & 175.363 & 13.747 & 3.601 & 0.003 & TRUE \\
\hline & $\begin{array}{l}\text { Cluster- } \\
219.21323\end{array}$ & 607 & $\begin{array}{l}9.70 \mathrm{E}- \\
14\end{array}$ & 10.035 & 19.630 & -0.900 & 0.898 & FALSE \\
\hline & $\begin{array}{l}\text { Cluster- } \\
13152.0\end{array}$ & 359 & $\begin{array}{l}4.80 \mathrm{E}- \\
37\end{array}$ & 2.112 & 0.482 & 1.798 & 0.986 & FALSE \\
\hline & $\begin{array}{l}\text { Cluster- } \\
13152.2\end{array}$ & 307 & $\begin{array}{l}8.60 \mathrm{E}- \\
43\end{array}$ & 0.760 & 0.000 & 1.979 & 0.986 & FALSE \\
\hline & $\begin{array}{l}\text { Cluster- } \\
219.2640\end{array}$ & 668 & $\begin{array}{l}5.70 \mathrm{E}- \\
23\end{array}$ & 4.413 & 8.486 & -0.944 & 0.983 & FALSE \\
\hline & $\begin{array}{l}\text { Cluster- } \\
219.46592\end{array}$ & 716 & $\begin{array}{l}5.70 \mathrm{E}- \\
114\end{array}$ & 47.137 & 76.689 & -0.678 & 0.957 & FALSE \\
\hline & $\begin{array}{l}\text { Cluster- } \\
219.50283\end{array}$ & 885 & $\begin{array}{l}2.00 \mathrm{E}- \\
20\end{array}$ & 476.302 & 27.677 & 4.100 & 0.000 & TRUE \\
\hline & $\begin{array}{l}\text { Cluster- } \\
17242.0\end{array}$ & 1683 & $\begin{array}{l}4.00 \mathrm{E}- \\
142\end{array}$ & 28.044 & 1.970 & 4.197 & 0.013 & TRUE \\
\hline & $\begin{array}{l}\text { Cluster- } \\
219.70351\end{array}$ & 626 & $\begin{array}{l}2.60 \mathrm{E}- \\
14\end{array}$ & 276.452 & 59.749 & 2.196 & 0.263 & FALSE \\
\hline & $\begin{array}{l}\text { Cluster- } \\
219.92608\end{array}$ & 1191 & $\begin{array}{l}2.70 \mathrm{E}- \\
23\end{array}$ & 404.993 & 14.361 & 4.867 & 0.000 & TRUE \\
\hline & $\begin{array}{l}\text { Cluster- } \\
219.29862\end{array}$ & 799 & $\begin{array}{l}1.40 \mathrm{E}- \\
15\end{array}$ & 29.500 & 18.531 & 0.661 & 0.806 & FALSE \\
\hline \multirow[t]{6}{*}{$\begin{array}{l}\text { TYDC ( } \\
6)\end{array}$} & $\begin{array}{l}\text { Cluster- } \\
219.138055\end{array}$ & 1681 & $\begin{array}{l}2.10 \mathrm{E}- \\
207\end{array}$ & 0.000 & 1.018 & -2.702 & 0.986 & FALSE \\
\hline & $\begin{array}{l}\text { Cluster- } \\
219.138056\end{array}$ & 789 & $\begin{array}{l}6.80 \mathrm{E}- \\
52\end{array}$ & 17.198 & 4.987 & 1.694 & 0.517 & FALSE \\
\hline & $\begin{array}{l}\text { Cluster- } \\
219.138245\end{array}$ & 1746 & $\begin{array}{l}6.70 \mathrm{E}- \\
225\end{array}$ & 89.068 & 46.722 & 0.916 & 0.986 & FALSE \\
\hline & $\begin{array}{l}\text { Cluster- } \\
219.138244\end{array}$ & 1722 & $\begin{array}{l}6.60 \mathrm{E}- \\
225\end{array}$ & 15.607 & 78.879 & -2.332 & 0.275 & FALSE \\
\hline & $\begin{array}{l}\text { Cluster- } \\
219.138246\end{array}$ & 1657 & $\begin{array}{l}2.10 \mathrm{E}- \\
207\end{array}$ & 0.000 & 2.035 & -3.668 & 0.960 & FALSE \\
\hline & $\begin{array}{l}\text { Cluster- } \\
219.128685\end{array}$ & 1215 & $\begin{array}{l}3.60 \mathrm{E}- \\
108\end{array}$ & 5.744 & 1.272 & 2.083 & 0.974 & FALSE \\
\hline
\end{tabular}

\section{Figures}




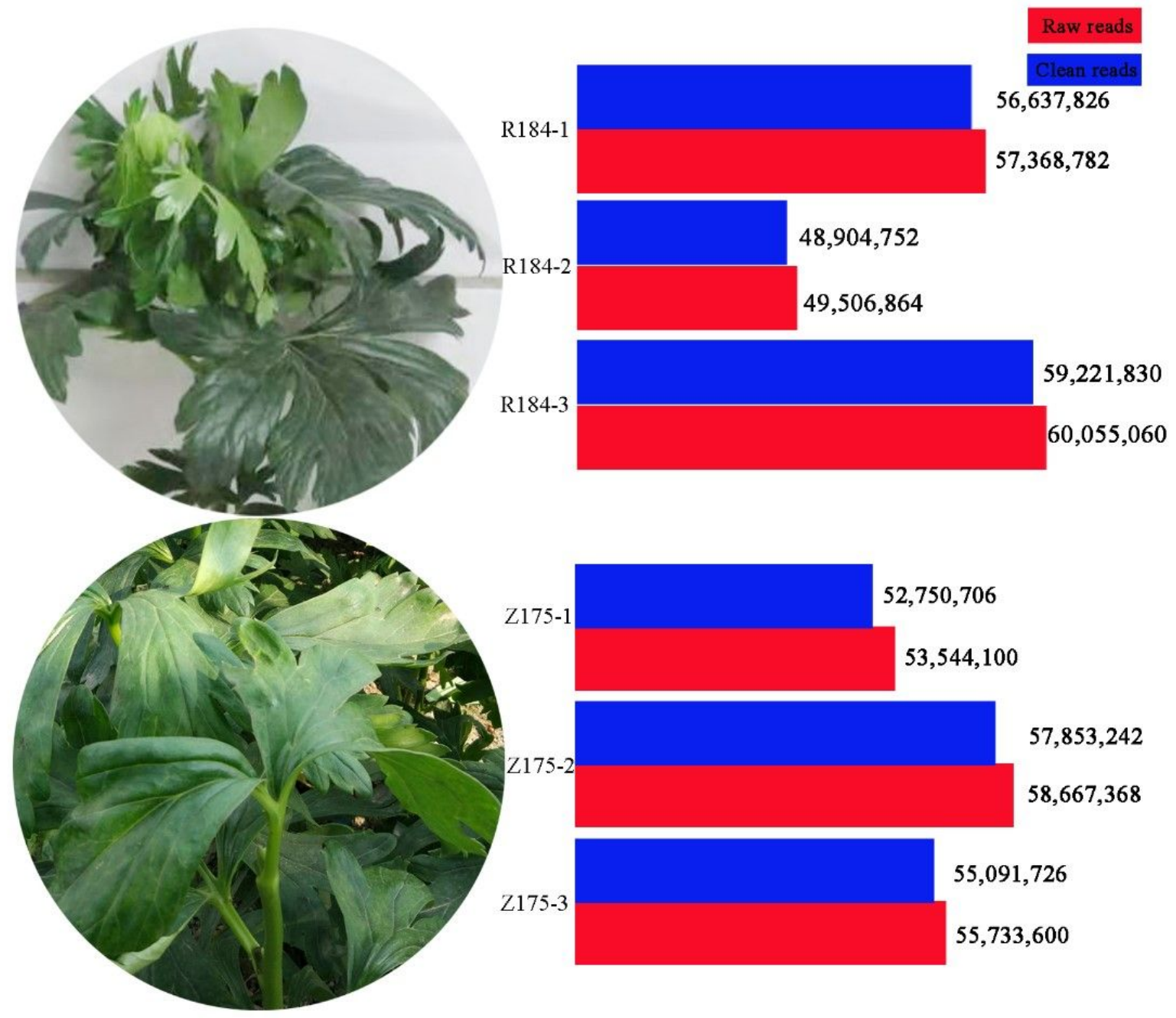

Figure 1

Raw and clean reads obtained from transcriptome analysis of different A. carmichaelii tissues. 


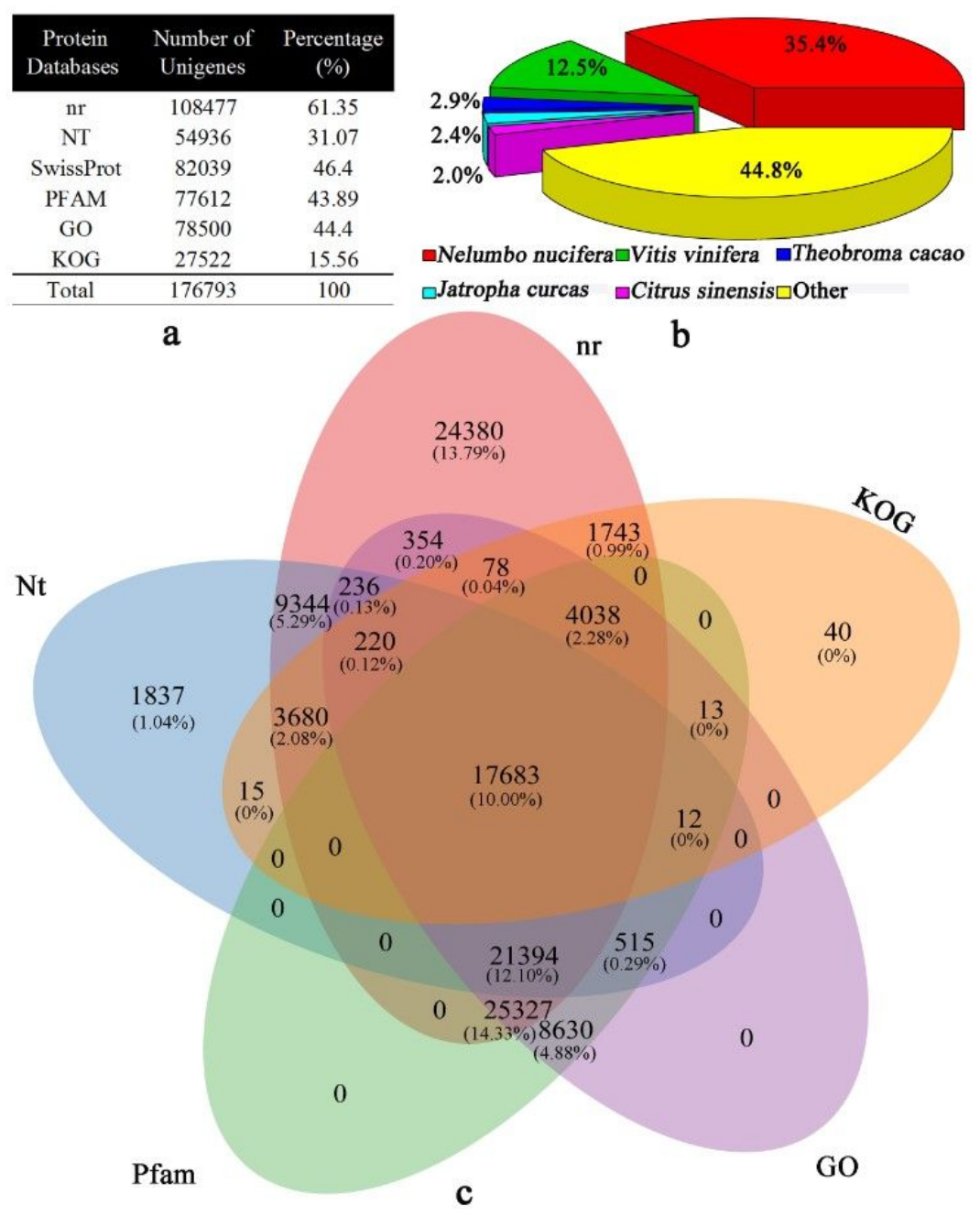

\section{Figure 2}

Statistical overview of functional annotation. (a) Functional annotation of unigenes using various public protein databases. (b) Unigenes in known species identified by BLASTx searches. (c) Venn diagram showing functional annotation of unigenes using NCBI non-redundant protein sequences (Nr), NCBI nucleotide sequences (Nt) , Swiss-Prot, Protein family (Pfam), Clusters of euKaryotic Ortholog Groups (KOG) and Gene Ontology (GO) databases. 


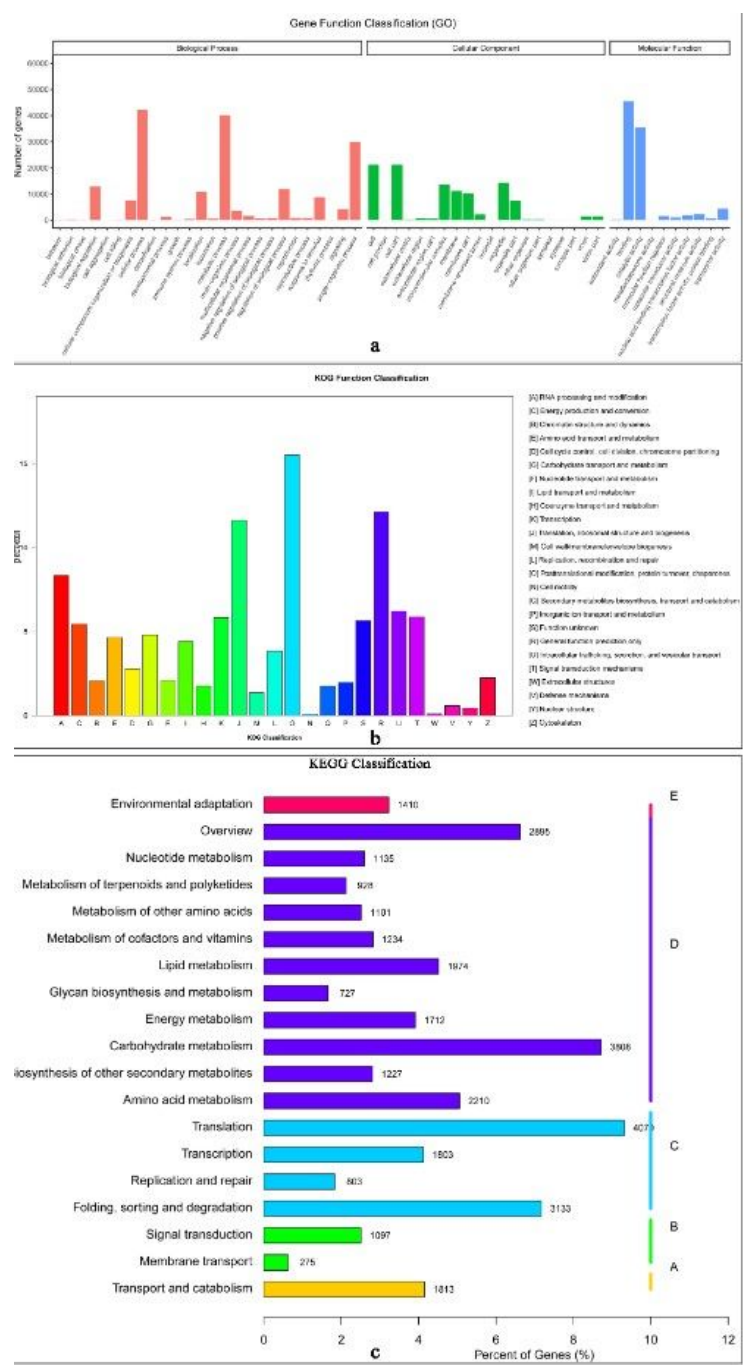

\section{Figure 3}

GO, KOG and Kyoto Encyclopedia of Genes and Genomes (KEGG) functional classification results. (a) GO function classification. (b) KOG functional classification. (c) KEGG functional classification.

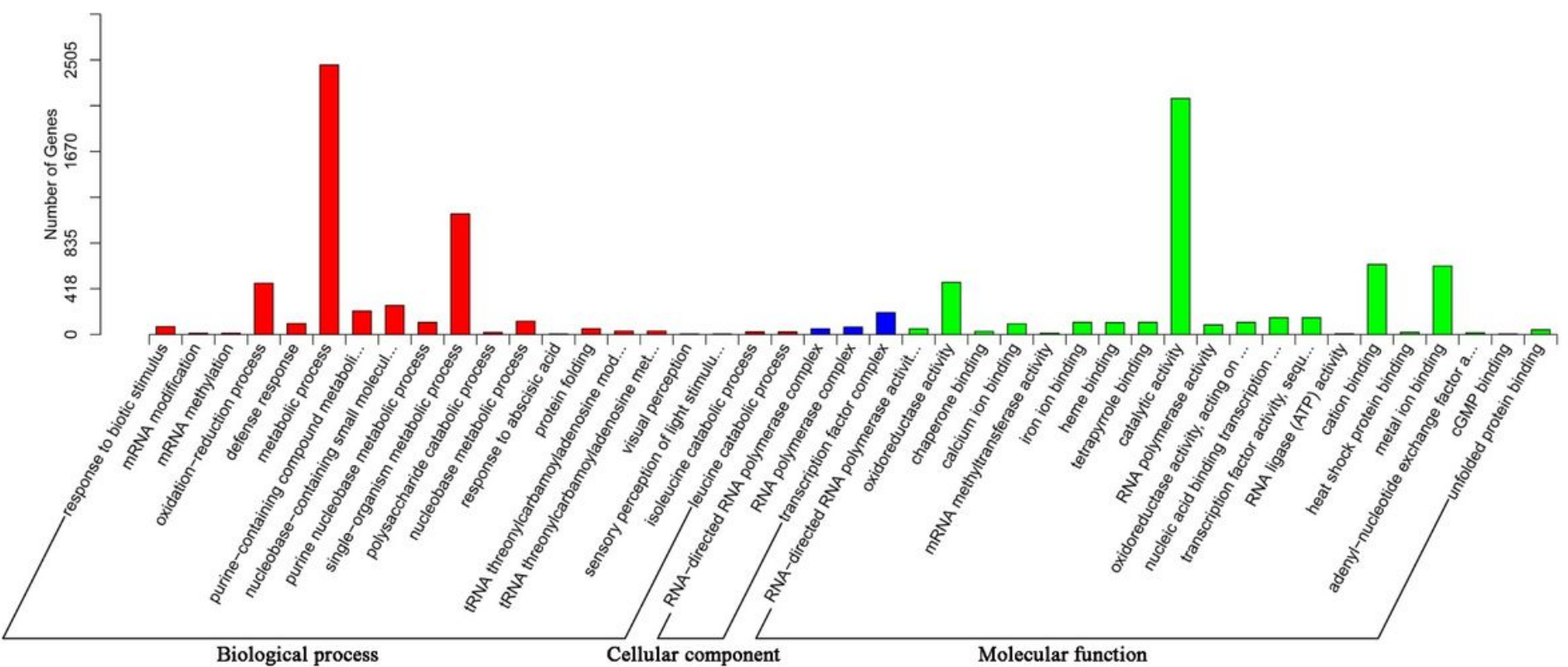

Figure 4 
GO enrichment analysis of DEGs between Z175 and R184 varieties.

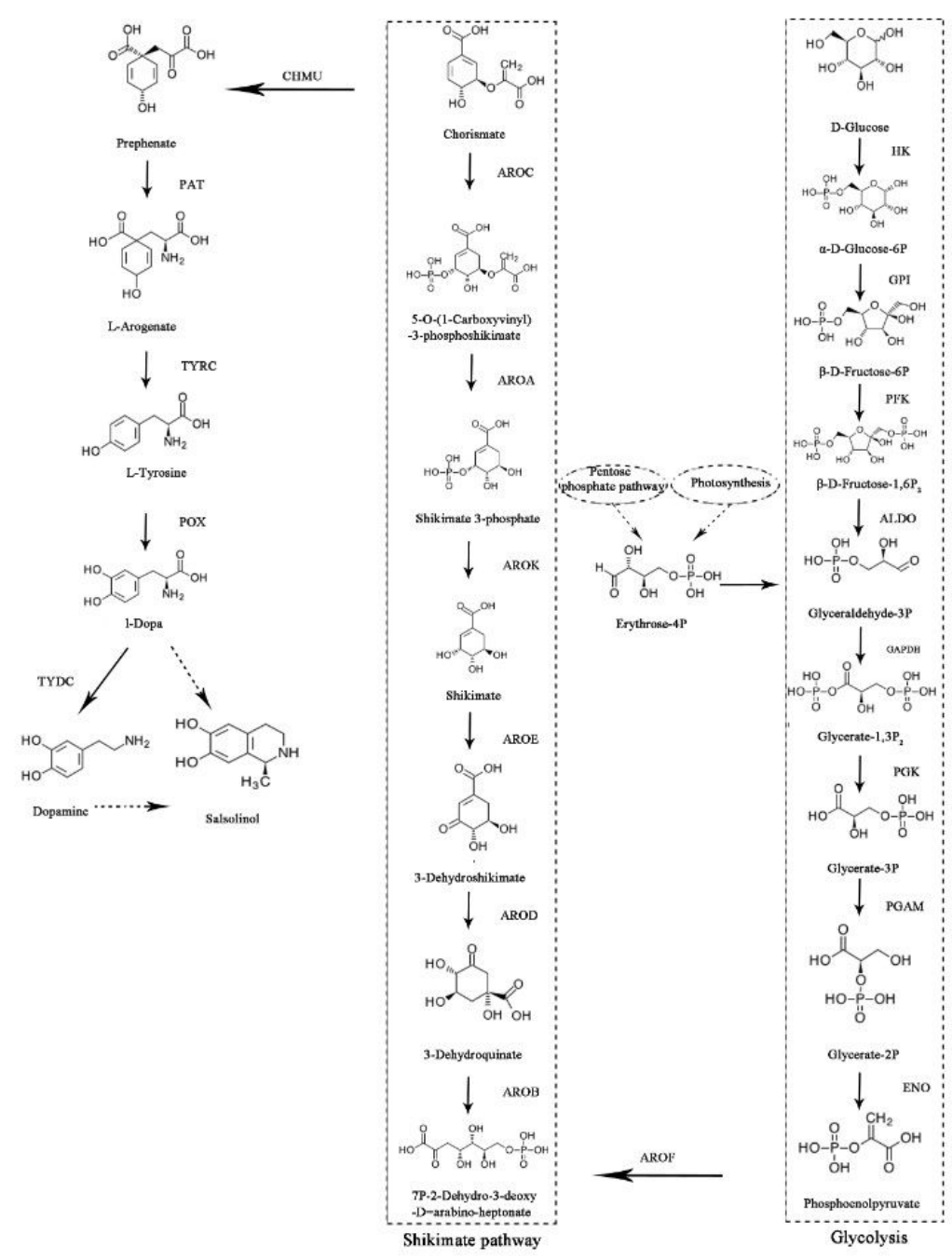

\section{Figure 5}

Salsolinol proposed biosynthesis pathway.

\section{Supplementary Files}

This is a list of supplementary files associated with this preprint. Click to download.

- supplement1.xlsx

- supplement2.xlsx

- supplement3.docx

- supplement4.docx

- supplement5.xlsx

- supplement6.xIsx

- supplement6.xlsx

- supplement8.xlsx 